\title{
Environmental and genetic influences on self-directed executive functioning in childhood
}

Jane Barker, Kaylyn van Deusen, Naomi P. Friedman \& Yuko Munakata

\begin{abstract}
Young children often struggle to accomplish goals without instructions or reminders from adults. Less-structured activities might facilitate children's emerging self-directed executive functioning, by giving children opportunities to choose what to do and when, and to practice setting and accomplishing goals. In one study, 6-year-old children who spent more time in less-structured activities showed better self-directed switching on a verbal fluency task; conversely, more time in adult-structured activities predicted worse switching (Barker et al., 2014). However, it is unclear from such correlational studies whether children's activities caused differences in executive functioning, as opposed to differences in executive functioning shaping how children spent time, or a third factor driving both. The current study thus investigated relationships between children's experiences and self-directed executive function in a genetically-informative longitudinal twin sample ( $\mathrm{N}=936 ; 472$ female, 464 male) . Twins who lived in more structured homes and participated in more structured activities at ages 3 and 4 showed worse self-directed switching on a verbal fluency task at age 7, controlling for earlier performance and concurrent levels of environmental structure. These relationships persisted controlling for general cognitive ability, vocabulary knowledge, and socioeconomic status. Associations between early time use and self-directed switching were mediated by nonshared environmental rather than genetic factors. These findings are consistent with early structured time causally affecting later self-directed executive function.
\end{abstract}




\section{Introduction}

In the absence of external reminders and instructions, young children often struggle to accomplish their intended goals. Lapses are common even when intentions are clear: a child might fail to get a permission form signed prior to an eagerly awaited field trip, for example, or not grab a coat before going outside to play on a chilly day. The ability to meet goals in a self-directed way, without instructions or reminders from adults, emerges slowly across development. Children accomplish goals independently by engaging executive functions, the cognitive control processes that regulate thought and action in support of goal-directed behavior. executive functions develop dramatically during childhood (e.g., Gathercole et al., 2004; McAuley et al., 2011; Munakata et al., 2012), and support a number of higher-level cognitive processes, including planning and decision-making, maintenance and manipulation of information in memory, inhibition of unwanted thoughts, feelings, and actions, and flexible shifting from one task to another (Miyake et al., 2000).

Early executive function ability has been shown to predict a range of important outcomes, including school readiness in preschoolers (e.g., Miller et al., 2013), and subsequent academic performance (Best et al., 2011; Blair \& Razza, 2007; Cameron et al., 2012; Samuels et al., 2016; St Clair-Thompson \& Gathercole, 2006). Children with poor self-regulation and self-control go on to have poorer health, wealth, and social outcomes in adulthood than children with better executive function (Moffitt et al., 2011; Robson et al., 2020).

Given the theoretical importance of executive functions to early self-regulatory success in academic settings, and established links between early executive functions and later life outcomes, executive functions have frequently been targeted for improvement via training and intervention studies (Diamond \& Lee, 2011; Diamond \& Ling, 2016; Otero et al., 2014; Takacs \& Kassai, 2019). Although interventions intended to improve executive functions have met with some success, lasting impacts of children's executive functioning in real-world contexts have rarely shown long-term persistence (Takacs \& Kassai, 2019). In training studies, short term improvements in executive function have largely been observed in laboratory tasks that are similar to tasks practiced during training, with limited transfer to untrained executive function skills (Kassai et al., 2019) or other 
cognitive domains (e.g., Blair \& Razza, 2007; Diamond \& Ling, 2016; Melby-Lervåg et al., 2016). Skills practiced during laboratory training sessions do not transfer to real-world settings, absent support contexts (Blair, 2017).

One interpretation of these findings is that improvement of executive functions requires sustained exposure to environments that promote emerging executive functions, and potentially, frequent opportunities engaging executive functions in a self-directed way, when rules and instructions are not provided by adults. Most benefits from training have been observed in EF tasks where instructions and reminders are provided by an experimenter. For example, children have shown improvement in lab-based 'flanker' tasks, where participants are asked to select a target button that matches a centrally-presented stimulus on a screen, ignoring distractor images that flank the sides of the stimulus (e.g., Lawler et al., 2019). Notably, children are given precise instructions about how and when to respond to stimuli during the task. Such context is often absent in real-world settings, where children must determine on their own how and when to engage executive functions.

Consistent with the idea that children's opportunities to engage executive functions in a self-directed way may benefit developing EF, two studies have found that children's exposure to less-structured environments -- rather than the adult-structured environments that are commonly the focus of training and intervention -- are associated with better EF in early childhood. In less-structured environments, adults allow children more latitude to determine on their own what goals they will pursue and how they will pursue them. Controlling for family income and child vocabulary, 6-year old children who spent more time in activities where rules and goals were not established by adults showed better self-directed executive function on a verbal fluency task, as measured by self-initiated switching among concepts to optimize performance (Barker et al., 2014). By contrast, children's time in structured environments such as adult-led lessons, clubs, and chores, marginally predicted worse EF. More recently, a study of children's daily schedules during the pandemic found that 3- to 5-year-olds who spent more time in less-structured activities showed better performance on the Dimensional Change Card Sort, a widely-used executive function task in which children must switch from sorting cards based on one dimension, such as color, to sorting 
based on another, such as shape (Stucke et al., 2021). Positive links in between children's time in less-structured activities and their shifting performance on the DCCS persisted after researchers controlled for age, family income, caregiver education, and verbal knowledge.

\section{Investigating Causal Links between Environmental Structure and Developing Self-directed EF in a Genetically Informative Sample}

Although contemporaneous links between children's time use and their executive functioning in early childhood are intriguing (Barker et al., 2014; Stucke et al., 2021), correlational designs cannot address questions of causality. We have hypothesized that children's time use may shape their developing executive function, such that children who have more opportunities for self-directed behavior develop better skills for engaging such behaviors in the absence of external reminders (Barker \& Munakata, 2015). Alternatively, children who are more successful in engaging executive functions in self-directed contexts may participate in (or be encouraged to participate in) less-structured activities more often; similarly, children who show worse self-direction may be encouraged to participate in structured activities. A third option is that observed links between executive function and time in less-structured activities are spurious, and instead driven by an unmeasured third variable. Given that executive functions are highly heritable (Friedman et al., 2016; Friedman et al., 2008; Miyake \& Friedman, 2012), parental executive function could be one such 'hidden' variable. For example, parents with better executive function may encourage their children, who have inherited better executive function, to engage in less-structured activities. We address these possibilities via two types of analyses.

First, we test for directional influence to determine whether earlier time in certain activities predicts later self-directed executive functioning, as we would predict if children's early exposure to specific environments causally impacts the development of executive function. Causal relationships based on theorized temporal precedence can be investigated via the cross-lagged panel design, where two constructs with a hypothesized causal relationship, X and Y, are assessed at two ages, so that the effect of $\mathrm{X}$ at age 1 on $\mathrm{Y}$ at age 2 can be estimated independent of $\mathrm{Y}$ at age 1 and $\mathrm{X}$ at age 2 (Kenny, 1975). By simultaneously modeling autoregressive paths, which assess the rank-order 
stability of each variable across time, and cross-lagged paths, which estimate the extent to which earlier scores on one variable relate to subsequent scores, we investigate whether directional influences between variables across time are consistent with a causal relationship between earlier time use and later executive function.

We test for directional influence between children's early time use and developing executive function within a large, genetically informative sample, the Colorado Longitudinal Twin Study (LTS). Consistent with prior investigations of time use and executive function (Barker et al., 2014), we used semantic verbal fluency as our measure of self-directed executive function. Unlike most lab-based executive function tasks, experimenters provide few task rules and reminders in semantic verbal fluency. During the task, participants are given a single categorical prompt (e.g., animals or foods), and attempt to produce as many exemplars from that category as possible in a given time interval, without additional reminders from an experimenter (Bechtoldt et al. 1962). Self-directed behavior on verbal fluency tasks is typically assessed via analysis of participant clustering and switching behaviors. Participants who produce many responses tend to cluster their responses by subcategory (Troyer et al., 1997; Troyer et al., 1998), and switch between clusters when novel response options dwindle. Thus, fluency measures indexing the total number of switches between recognizable clusters (e.g., from zoo animals to farm animals) are considered a good index of self-guided, internally-directed search processes (Abwender et al., 2001; Snyder \& Munakata, 2010; Troyer et al., 1997).

Children continue to improve in verbal fluency switching and production well into adolescence (Ardila et al., 2005; Kave et al., 2008; Koren et al., 2005; Matute et al., 2004; Riva et al., 2000; Sauzéon et al., 2004; Welsh, 1991), after they show adult-like performance on externally-driven EF tasks (Hurks et al., 2010; Kavé et al., 2008; Klenberg et al., 2001; Koren et al., 2005; Sauzéon et al., 2004; Welsh, 1991). Improvements in switching ability persist after children produce clusters that are indistinguishable in size from those of adults (Hurks et al., 2010). These findings collectively suggest that the ability to engage executive functions in self-directed contexts may draw on distinct, slow-developing cognitive processes or abilities. 
Latent factors for twins' verbal fluency switching ability, participation in structured activities, and household characteristics theorized to support child autonomy were generated from multiple tasks and instruments at three time points across development. Testing relationships between constructs at the latent variable level reduces measurement error by extracting variance common across each indicator, resulting in better estimates of each child's true score for each construct at each time point.

Second, we test for the potential influence of genetic factors on observed relationships between structured environments and self-directed executive functioning. Cross-lagged panel analyses do not afford true causal inference, as even temporal relationships - such as earlier time in structured activities predicting later self-directed executive functioning - may reflect non-causal factors, including shared genetic influence across parents and children. For example, parental genotypes might contribute to each construct via genetic influences on children's self-directed EF, and via choices that influence shared environmental experiences in the home (e.g., typical patterns of time use). Inherited traits may simultaneously influence how children shape their environments (e.g., children with better self-directed EF may seek out different experiences, shaping patterns of time use) or passively elicit changes in the environment (e.g., children with low self-directed forms of EF may be enrolled in more structured activities, changing patterns of time use). Each example is a form of gene by environment correlation, which independently and collectively constitute sources of genetic mediation. Such explanations are plausible in the case of verbal fluency, as other forms of executive function are highly heritable in childhood (Engelhardt et al., 2015) and in adults (Friedman et al., 2008).

To test for the impact of genetic mediation on proposed causal relationships, we use a multivariate extension of the classic twin design, which uses twin correlations from monozygotic (MZ) and dizygotic (DZ) pairs to estimate the extent to which variation in individual traits and abilities can be attributed to additive genetic (A; heritability), shared environmental (C), and nonshared environmental (E) sources of influence. If children's early exposure to specific environments causally impacts the development of executive function, observed relationships 
between early structured activity participation and later self-directed executive function should be mediated by environmental factors. Alternatively, if links between early environmental structure and later verbal fluency are mediated by shared genetic factors, observed links may reflect a passive gene-environment correlation (e.g., parents pass genes contributing to higher EF to their children, and are also more likely to enroll their children in structured activities). Twin modeling techniques draw on three sources of information: MZ twins share all their genes; DZ twins share on average half their genes by descent; and typically-reared twins share a common family environment. Given these conditions, phenotypes that show higher MZ within-pair correlations than DZ within-pair correlations suggest the presence of genetic influence on that phenotype. Multivariate genetic methods extend the basic ACE model to test whether cross-lagged paths between two variables at two time points are mediated by environmental or genetic influences (Luo et al., 2010).

In addition to testing genetic mediation of observed longitudinal relationships, we also explore genetic and environmental contributions to time use and self-directed executive function, which have not been previously investigated in longitudinal developmental samples. Despite its frequent use in both clinical and experimental settings, genetically-informed studies of verbal fluency have focused exclusively on total word production, rather than more specific switching indices. Multiple adult studies have shown both genetic and environmental contributions to performance on verbal fluency tasks (Hayiou-Thomas et al., 2006; Kavé et al., 2013; Kovas et al., 2005; Owens et al., 2011; Swan \& Carmelli, 2002) and find that by middle age, approximately 45\% of the variance verbal fluency performance is explained by genetic contributions (Gustavson et al., 2018; Jones-Odeh et al., 2016; Sakakibara et al., 2018). Only one study has focused on a developmental sample (Kavé et al., 2013), and that work was limited to 4-year-olds, who show only nascent executive abilities. Modeling switch scores provides a more robust estimate of developmental changes in self-directed forms of EF, since total production is influenced by both executive and non-executive abilities (e.g., vocabulary Unsworth et al., 2012). Similarly, investigations of genetic and environmental influences on child time use have largely focused on differences in physical activity and sedentary behaviors, and most have not explicitly modeled 
genetic contributions to structured versus less-structured leisure time. These studies generally show strong contributions to child time from shared environmental influences in young children, with increasing contributions from genetic influences in adolescence and beyond (Aaltonen et al., 2010; Stubbe et al., 2005). Only two studies have focused on pre-adolescent children, and both found no evidence of genetic influence on measures of physical activity. A study of physical activity expenditure in 4- 10 year old twins found that shared environmental influences accounted for the majority of familial resemblance across twins (Franks et al., 2005). In a second sample of 9 - 12 year-old twins, shared environment effects explained the majority (73\%) of the variance in an accelerator-recorded measure of total physical activity over 7 days, with a smaller unshared environmental effect, and no significant genetic effect. In comparison, children's self-reported activity preferences showed a strong genetic contribution, and no significant contribution from shared environments (Fisher et al., 2010).

Findings from this study will thus address causal questions about the relationship between children's activities and executive function by: (1) testing longitudinal relationships between children's structured activity participation and self-directed executive function using standard cross-lagged panel designs, (2) testing environmental and genetic mediation of those relationships, and (3) testing genetic and environmental contributions to activities and self-directed executive function in childhood.

\section{Method}

\section{Sample}

The sample included 936 individuals from 468 twin pairs recruited from the Colorado Longitudinal Twin Study. Of those twins, 506 were MZ (266 female, 240 male) and 430 were DZ (206 female, 224 male). ${ }^{1}$ Families were located through birth records provided by the Division of Vital Statistics of the Colorado Department of Health from 1986 through 1990. Enrollment criteria

\footnotetext{
${ }^{1}$ This number includes all twins who completed one or more study tasks or questionnaires. As detailed in Table 3.2, twin enrollment varied across the 12-year study interval, and not all twins completed all measures at each time point.
} 
included normal birth weight and gestation period, and a residence located within 2 hours of Boulder, Colorado; detailed information on sample characteristics is available in Rhea et al., (2006). Participants received compensation for each testing session. Zygosity was initially determined from parent and tester ratings on a zygosity questionnaire (Nichols \& Bilbro, 1966) and subsequently confirmed via DNA genotyping for twins who remained enrolled in the study. For those twins, zygosity was confirmed via examination of twin concordance across a minimum of 11 highly information short tandem repeat (STR) polymorphisms.

\section{Tasks and Measures}

Twins completed verbal fluency prompts at ages 4, 7, and 16 years. Parents reported activity participation for each twin at corresponding time points, and information about family household characteristics when twins were aged 3, 7, and 15. Details about tasks and measures at each age are provided in the following sections.

\section{Semantic Verbal Fluency}

Twins independently completed three verbal fluency prompts at ages 4 and 7, and two at age 16 as part of a Specific Cognitive Abilities battery that included verbal, spatial, memory, and perceptual speed subtests. ${ }^{2}$ Prompts were administered during a home visit at age 4 , and in the laboratory thereafter.

Task prompts, administration and duration varied by age (Table 3.1). At age 4, the experimenter instructed the child, "Let's play a word game. I will tell you something that makes noise, and then you tell me something that makes noise that is different. How about a whistle. Now you tell me something that makes noise." If the child repeated the example (a whistle), the experimenter corrected the child, saying, "I told you about the whistle, now you tell me something different that makes noise." If the child did not appear to understand the task, the experimenter repeated the previous instructions, this time substituting 'radio' for whistle. After practice, the

\footnotetext{
${ }^{2}$ This battery was used to derive general cognitive ability ( $g$-factor) in the present study.
} 
experimenter said, "Now tell me all the things that you know make noise." Children were then given $30 \mathrm{~s}$ to respond to each prompt. If the participant appeared to lose interest or stopped producing words during the test phase, the experimenter prompted, "Can you tell me some more things that make noise?" This process was repeated for each of 3 prompts (things that make noise, are soft, or are round), with primary and secondary examples varying by prompt (soft examples were 'blanket'/'pillows', round examples were 'ball'/'wheels'). At age 7, twins responded verbally to three oral prompts: 'Tell me all the animals you can think of', 'Tell me all the things you can think of that are round', '...that are made of metal'. Children were given 1 minute to respond to each prompt. At age 16, semantic verbal fluency was administered in a written format. Twins completed the prompts "List at the things you can think of [that are made of metal]/ [that are round]." Twins were given 3 minutes to respond to each prompt, and were not allowed to proceed to the second prompt until the full time for the first prompt had elapsed.

Responses to each prompt were transcribed and coded for switches between semantic subcategories. ${ }^{3}$ Coders were trained to identify clusters of items that were semantically related (e.g., "dog", "cat", "gerbil") to demarcate between-cluster switches. As in past work, the final switch score for each prompt was weighted by cluster size, reflecting the prediction that confidence in clustering and switching behavior should increase as cluster size increases (Barker et al., 2014; Snyder \& Munakata, 2010, 2013). However, we modified this weighting procedure in the present study to address the concern that the simple weighting procedure used in past work (where each cluster contributed N-1 words to the total switch score for that prompt) could be biased in the presence of large cluster sizes. If children generate large clusters and switch infrequently, the switch score measure could be more likely to reflect factors that support production within clusters, such as semantic network density, rather than processes specifically supporting switching across clusters. We therefore modified the weighting procedure in the present study to incorporate a logarithmic

\footnotetext{
${ }^{3}$ Children sometimes repeated experimenter-provided examples at age 4 . These responses were removed from the dataset prior to the generation of production and switching indices.
} 
adjustment that reduced the contribution of large clusters to the overall switch score. The switch score $S$ of participant $i$ was calculated according to:

$$
S_{i}=\sum_{c}^{C} \log \left(s_{c}\right)
$$

where the switch score $S_{i}$ was calculated as the sum over $C \log$-adjusted clusters of size $s_{c}$, where $s_{c}$ was defined as the number of words in the cluster. All prompts were scored by two coders, and both production and switching indices were averaged across coders. As in past work, coders demonstrated good inter-rater reliability for switch scores at each time point (all $r s>.85$ ).

\section{Child structured activity participation}

Indices reflecting children's participation in structured and less-structured activities were generated from items taken from the Child Behavior Checklist (CBCL) (Achenbach \& Edelbrock, 1983) and an Interests and Activities Survey (IAS).

CBCL. The CBCL was administered to parents when twins were 4, 7, and 16 years old. Reporting format varied slightly at each time point. At age 4, parents indicated sports, clubs, and chores each twin participated in or completed, and rated the amount of time each twin spent in each activity relative to other children ("less than average", "average", "more than average", "don't know"). Reported activities were weighted according to parent-reported time spent in that Table 1: LTS Structured Time and Verbal Fluency Measures at Ages 4, 7, and 16 Years.

\begin{tabular}{lll}
\hline Time & Child structured activity participation & Verbal fluency prompts \\
\hline Age 4 & CBCL Activity Items: & 'Things that are round' \\
& Structured Lessons \& & 'Things that are soft' \\
& Activities & 'Things that make noise' \\
& Clubs/Organizations & \\
& Chores & \\
\hline
\end{tabular}


Age 7
CBCL Activity Items:

Structured Lessons \&

Activities

Clubs/Organizations

Chores Interests and

Activities Survey

Structured Lessons \&

Activities

Activities

CBCL Activity Items:

Clubs Chores
'Things that are round'

'Things made of metal'

'Animals'

Age 16

Clubs Chores

'Things that are round' 'Things made of metal'

Note: CBCL = Child Behavior Checklist; MFES: Moos Family Environment Scale; IAS = Interests and Activities Survey. $\uparrow$ The MFES was independently administered to one or both parents at each time point. $\ddagger$ The IAS was independently administered to one or both parents at age 7. Ratings were averaged to form composites when information from both parents was available.

activity ${ }^{4}$ and rated for relative level of structure using established criteria ( Eccles \& Barber, 1999; Fletcher et al., 2003; Hofferth \& Sandberg, 2001b; Mahoney \& Stattin, 2000; Meeks \& Mauldin, 1990; Osgood et al., 2005). As in prior work (Barker et al., 2014), structured activities included adult-led lessons and practices (e.g, basketball, soccer, martial arts, music), organizational meetings or events (Girl/Boy Scouts, YMCA groups), and chores (housework, cleaning). Activities were summed to form composite scores for time in structured activities. At age 7, parents completed just two items: an activity item (resulting in combined reporting of clubs and sports), and a chore item. At age 16, parents reported club involvement and chore completion. As in year 4, parents rated time spent in each activity at 7 and 16, and weighted composites were formed.

Interests and Activities Survey. At age 7, parents indicated twin participation in structured lessons and activities. This measure included both elicited and free-response items.

\section{Household Structure}

Moos Family Environment Survey (MFES). Household control and organization subscales were used to represent levels of household structure. Each subscale included items related to control over

\footnotetext{
${ }^{4}$ Parents did not report level of participation in chores; therefore, the chore variable represents the total number of chores reported.
} 
the home environment, e.g., "There are set ways of doing things at home”, "Each person's duties are clearly defined in our family". Full scales at each age are given in Appendix A.

Items were scored true/false (0/1) at age 3, and on a 5 point Likert scale at Y7 and Y15.

\section{Covariates}

We measured several factors that might relate to both verbal fluency and structured environments. For example, children with lower cognitive or verbal ability might be encouraged to enroll in activities to improve language acquisition, or children from high-SES homes might be given more opportunity to enroll in structured activities and also show strong verbal fluency performance.

General cognitive ability (g-factor). General cognitive ability (g) was calculated as the first principal component of child performance within a specific cognitive battery comprised of verbal, spatial, memory, and perceptual speed subtests. Subtests are described in detail in Kent \& Plomin ( 1987) and Appendix C. Testers administered the battery during a home visit when twins were 4, and in the laboratory at years 7 and 16.

Vocabulary. Vocabulary was measured using the vocabulary subtests of the Wechsler Preschool and Primary Scale of Intelligence (WPPSI) at age 4, the Wechsler Intelligence Scale for ChildrenRevised (WISC-R) at age 7, and the Wechsler Adult Intelligence Scale III (WAIS) (Wechsler, 1974) at age 16. Scaled scores were used at each age.

Parent occupational ratings. Occupational ratings for each parent were derived using the Revised National Opinion Research Center ratings of occupation status of the parents at the time of the 14-month testing (Hauser \& Featherman, 1977). Ratings were z-transformed in mothers and fathers, then averaged to form a single indicator for each family.

\section{Results}

\section{Analytical Approach}

All analyses were conducted using Mplus version 7.31 (Muthén \& Muthén, 2012). Models that included categorical (binned) indicators were estimated using weighted least squares, mean and 
variance adjusted (WLSMV); all other models were estimated using full-information maximum likelihood. In phenotypic analysis, the MPlus 'type = complex' option was used to generate robust chi-squares and standard errors adjusted for clustering within twin families. In genetic analyses, each twin was assigned a number (twin 1 or twin 2) using the same random assignments used in prior work (e.g. Friedman et al., 2008). Model fit was evaluated via overall chi-square $\left(\chi^{2}\right)$ tests, as well as two tests insensitive to sample size: comparative fit index (CFI) and root-mean-square error of approximation (RMSEA). Established fit thresholds were used for each test, with RMSEA $<.06$ and CFI > .95 representing good fit ( $\mathrm{Hu} \&$ Bentler, 1999). Chi-squared difference tests were used to evaluate the significance of individual paths $\left(\chi_{\text {diff }}^{2}\right)$ In WLSMV models, significance was tested using the DIFFTEST option; in phenotypic models using the robust maximum likelihood estimator, significance was tested using Satorra-Bentler Scaled Chi-Square estimates $\left(\chi^{2 \mathbf{S B}}{ }_{\text {diff }}\right)$.

The distributions of all variables were examined for non-normality, since indicator nonnormality can increase the standard errors of maximum likelihood parameter estimates, resulting in poorer estimates of model fit (West et al., 1995). Variables that showed excess skewness or kurtosis were initially log-transformed. Because age-4 and age-7 VF prompts (apart from the age-7 'animals' prompt) continued to show censored, right-skewed distributions after transformation, problem indicators were binned into categorical variables. Year-4 prompts were coded such that switch scores of $0=1$; switch scores $>0$ and $<=1=2$; and scores $>1=3$. Year-7 prompts (apart from 'animals', which showed acceptable skewness and kurtosis after transformation) were coded such that $1=$ switch score of $0 ; 2=$ switch score $>0$ and $<1 ; 3=$ switch score $>1$ and $<2.5$; and $4=$ switch score $>2.5$.

Finally, we note that we have foregone traditional tests of longitudinal measure invariance (which constrain factor loadings over time to test whether factors are interpreted similarly at different ages) because several measures were administered at some time points but not others. Inconsistency in measure availability results in differences in latent factor composition across time. As such, the present analyses cannot be used to investigate the stability of construct measurement 
across time and subpopulations (e.g., males versus females), or to evaluate within-person change in a construct (e.g., with a latent growth model). Instead, these models can be interpreted as reflecting individual differences in each construct at each time point, and the relations of those between-subject differences across time (Berry \& Willoughby, 2017).

Descriptive statistics for structured activity participation, verbal fluency switching, and covariate variables are given in Table 2 , along with twin 1/twin2 correlations for MZ and DZ twins. Categorical variable bins and twin 1/twin 2 correlations are provided in Table 2.3. Bivariate correlations for all measures are provided in Appendix A.

\section{Phenotypic longitudinal panel models}

To test relationships between child structured activity participation, household structure and children's verbal fluency switching performance across time, latent factors for verbal fluency switching performance and structured activity participation were fit to a series of phenotypic cross-lagged panel models. Each model tests whether age-4 indicators for each construct are predictive of corresponding indicators at later ages, controlling for earlier levels of each construct. For example, in Figure 1, paths B1 and B2 reflect autoregressive effects, or the effect of a construct on itself measured at a later time, reflecting the stability of individual differences in that construct from one time point to the next. Paths B3 and B4 represent cross-lagged effects of one construct on another at a later time point.

Children's structured activity participation and household-level structure were initially investigated in discrete panel models. This approach was taken for two reasons. First, indicators measuring family-level characteristics cannot be measured using standard twin methods, which capitalize on differences between twins in the same household; family-level reports do not capture such differences. Therefore, genetically-informative twin-level factors were developed independently of household-level factors to investigate the relative influence of genetic and environmental factors to observed relationships. Additionally, for theoretical reasons, combining indicators measuring traits at the level of the individual (structure time participation) with those 
measuring differences at the level of a family unit (household characteristics) likely results in a combined factor that captures variance across distinct constructs. Thus, while household levels of familial structure and twin-level measures of structured activity participation are correlated in the present study, they are analyzed in separate models.

We conducted several secondary models to test whether hypothesized third variables could explain any observed relationships between structured activity participation, household structure, and verbal fluency switching ability. Basic panel models relating each construct to verbal fluency performance were subsequently augmented with child general cognitive ability (g factor), vocabulary, and parent occupational ratings (as a proxy for SES).

In addition to tests controlling for general cognitive ability and vocabulary, which evaluate whether relationships with verbal fluency were specific, or could instead be explained by other factors (general cognitive factors and/or crystallized intelligence), we conducted two tests exploring whether measures of semantic knowledge showed similar relationships with environmental structure. If exposure to structure affected affected children's vocabulary or semantic network development (or, alternatively, if such abilities affected their exposure to structure), we might predict subsequent changes in average verbal fluency cluster size, which shows stronger correlations with vocabulary than switching measures in adults (Unsworth et al., 2011; Lanting et al., 2009). If relationships between verbal fluency performance and environmental structure are driven by changes in semantic networks rather than changes in self-directed switching ability, we would predict vocabulary performance and cluster size measures might show similar patterns with measures of structure across time. We note, however, that cluster size and switching indices are particularly difficult to dissociate in young children who generate few switches and relatively small clusters; in such cases, clustering and switching measures are highly overlapping.

\section{Structured activity participation and verbal fluency switching ability}

To examine longitudinal associations between structured activity participation and verbal fluency switching ability, we first tested baseline models relating verbal fluency to structured 
activity participation from age 4 to age 7 . Measurement residual correlations that significantly improved model fit were retained in all analyses. ${ }^{5} \mathrm{~A}$ basic measurement model with no autoregressive paths showed poor model fit $\left(\chi^{2}(48)=84.06, p=.001\right.$; CFI $=.882$; RMSEA $\left.=.029\right)$. Inclusion of autoregressive paths from $\mathrm{T} 1$ to $\mathrm{T} 2$ and within-time correlations at $\mathrm{T} 1$ significantly improved model fit (M1; Table 4), and showed similar fit to a model including within-time correlations at T2 (M2). Adding cross-paths between traits at T1 and T2 improved fit relative to each model and yielded good overall fit $\left(\mathrm{M} 3 ; \chi^{2}(46)=61.78, p=.060 ; \mathrm{CFI}=.950\right.$; RMSEA $\left.=.018\right)$.

The full cross-path model demonstrates that opposing influences may contribute to observed links between structured activity participation and verbal fluency switching ability (Figure 1). Children who participated in more structured activities at age 4 showed marginally worse verbal fluency switching performance at age 7, controlling for earlier verbal fluency ability and contemporaneous structured time (path $\mathrm{B}_{4} ; \beta=-.22 ; \chi_{\text {diff }}^{2}(1)=2.97 ; \mathrm{p}=.085$ ). This finding is consistent with the causal inference that early participation in structured activities contributes to worse self-directed EF later in childhood. Unexpectedly, the cross-path linking early verbal fluency to later structured activity participation was significant in the opposite direction, indicating that children with better verbal fluency switching ability at age 4 went on to participate in more structured activities at age 7, controlling for earlier participation in structured activities and contemporaneous verbal fluency switching ability (path $\mathrm{B}_{3} ; \beta=.30 ; \chi_{\text {diff }}^{2}(1)=5.91 ; \mathrm{p}=.015$ ). This finding is consistent with a causal influence of children's early verbal fluency ability on subsequent structured activity participation. Such a pattern could indicate that children

\footnotetext{
${ }^{5}$ Residual correlations between chore indicators and structured activity measures significantly improved model fit, and were added to all models.
} 
Table 2: Descriptive Statistics for Continuous Measures Used in the Longitudinal Analysis.

\begin{tabular}{|c|c|c|c|c|c|c|c|c|}
\hline & $\mathrm{N}$ & Mean & SD & Range & Skewness & Kurtosis & $r \mathrm{MZ}$ & $r \mathrm{DZ}$ \\
\hline \multicolumn{9}{|l|}{ Age 3 - 4 years } \\
\hline \multicolumn{9}{|l|}{ Structured Activities } \\
\hline CBCL Activities & 591 & 1.15 & .92 & $0.00-4.50$ & -.132 & .865 & .99 & .88 \\
\hline CBCL Chores & 591 & 1.37 & 1.01 & $0.00-3.00$ & .175 & -1.17 & .99 & .95 \\
\hline CBCL Clubs & 591 & .303 & .58 & $0.00-3.00$ & 1.57 & 1.34 & .99 & .97 \\
\hline \multicolumn{9}{|l|}{ Household Structure } \\
\hline FES Control & 478 & 7.79 & 1.37 & $1.50-10.00$ & -.261 & -.421 & - & - \\
\hline FES Organization & 478 & 3.23 & 1.26 & $0.00-5.00$ & -.364 & -.92 & - & - \\
\hline$g$-Factor & 704 & -.386 & 1.17 & $-5.39-3.28$ & .024 & .520 & - & - \\
\hline \multicolumn{9}{|l|}{ Parental Occupation } \\
\hline \multicolumn{9}{|l|}{ Age 7 years } \\
\hline \multicolumn{9}{|l|}{ Structured Activities } \\
\hline CBCL Chores & 633 & 2.19 & .85 & $0.00-3.00$ & -.884 & -.067 & .96 & .86 \\
\hline IAS Lessons & 632 & 2.95 & 1.69 & $0.00-8.00$ & .17 & -.36 & .95 & .93 \\
\hline \multicolumn{9}{|l|}{ Household Structure } \\
\hline FES Control & 478 & 29.52 & 3.69 & $14.00-41.00$ & -.261 & -.421 & - & - \\
\hline FES Organization & 478 & 30.94 & 5.01 & $16.00-43.00$ & -.364 & -.920 & - & - \\
\hline \multicolumn{9}{|l|}{ Verbal Fluency } \\
\hline Animal & 696 & 4.69 & 1.86 & $0.00-10.23$ & .318 & -.217 & .42 & .16 \\
\hline$g$-Factor & 811 & 0.00 & 1.00 & $-4.22-2.87$ & -.165 & .403 & - & - \\
\hline Vocabulary & 820 & 10.41 & 2.89 & $1.00-19.00$ & .150 & .201 & - & - \\
\hline \multicolumn{9}{|l|}{ Age 16 years } \\
\hline CBCL Clubs & 489 & 2.20 & 1.43 & $0.00-4.50$ & -.10 & -1.11 & - & - \\
\hline CBCL Chores & 489 & 2.34 & 1.18 & $0.00-4.50$ & -.30 & -.69 & - & - \\
\hline \multicolumn{9}{|l|}{ Household Structure } \\
\hline FES Control & 346 & 17.15 & 3.46 & $6.00-25.00$ & -.358 & .285 & - & - \\
\hline FES Organization & 346 & 17.45 & 3.84 & $8.00-25.00$ & -.342 & -.634 & - & - \\
\hline \multicolumn{9}{|l|}{ Verbal Fluency } \\
\hline Round & 808 & 3.77 & 2.32 & $0.00-14.23$ & .75 & .55 & - & - \\
\hline Metal & 806 & 4.35 & 2.72 & $0.00-14.95$ & .60 & .03 & - & - \\
\hline$g$-Factor & 571 & .640 & $-3.27-3.78$ & -.324 & .197 & - & - & \\
\hline Vocabulary & 572 & 11.24 & 2.82 & $4.00-19.00$ & .094 & -.146 & - & - \\
\hline $\begin{array}{l}\text { Parental Occupational } \\
\text { Ratings (14 months) }\end{array}$ & 792 & .010 & .771 & $-1.63-2.31$ & .285 & -.257 & - & - \\
\hline
\end{tabular}

Note: All correlations significant at $\mathrm{p}<.05$. Means, SDs, and ranges represent untransformed values, and reported skewness and kurtosis values are post-transformation. 
Table 3: Bin Values for Categorical Variables.

\begin{tabular}{|c|c|c|c|c|c|}
\hline & & \multicolumn{3}{|c|}{ Age 4} & Age 7 \\
\hline Bin Number & Noise & Round & Soft & Round & Metal \\
\hline 1 & 401 & 613 & 472 & 120 & 263 \\
\hline 2 & 185 & 118 & 172 & 243 & 215 \\
\hline 3 & 148 & - & 87 & 206 & 145 \\
\hline 4 & - & - & - & 127 & 73 \\
\hline Total N & 734 & 731 & 731 & 696 & 696 \\
\hline MZ Correlation & .36 & .31 & .18 & .11 & .31 \\
\hline DZ Correlation & .29 & .01 & .07 & .04 & .22 \\
\hline
\end{tabular}

Note: Within-task participant attrition resulted in a change in $\mathrm{N}$ across the three verbal fluency prompts at age 4 . Significant correlations signified by bold text $(p<.05)$.

Table 4: Links between Child Structured Activity Participation and Verbal Fluency Switching Ability.

\begin{tabular}{|c|c|c|c|c|c|c|c|}
\hline Model Comparison & $\chi^{2}$ & $\mathrm{df}$ & $\mathrm{p}$ & CFI & RMSEA & $\chi^{2 \text { diff }}$ & $\begin{array}{l}\mathrm{d} \\
\mathrm{f}\end{array}$ \\
\hline M1: Stability and Time 1 Correlation & 74.05 & 48 & .009 & .915 & .025 & & \\
\hline M2: Correlated Change Model & 74.78 & 47 & .006 & .909 & .026 & .149 & 1 \\
\hline M3: Addition of Cross-paths & 62.95 & 45 & .039 & .941 & .021 & $9.32^{*}$ & 2 \\
\hline
\end{tabular}

Note: ${ }^{*} \mathrm{p}<.01$

with better self-directed EF at age 4 seek out or are encouraged to enroll in more structured activities at age 7 . These competing influences could explain why time in structured activities showed weak within-time correlations with verbal fluency switching performance (Barker et al., 2014), and are explored further in subsequent sections.

\section{Tests of SES and Vocabulary as Hidden Variables}

To test whether verbal fluency switching ability serves as a proxy for an unknown variable that influences both time use and verbal fluency performance, we conducted focused tests controlling for vocabulary and SES. If either vocabulary or SES exert simultaneous causal influences on children's enrollment in structured activities in early childhood and verbal fluency performance, 
controlling for their influence will likely attenuate cross-lagged paths between earlier and later levels of each construct.

Controlling for children's vocabulary at each age did not attenuate the observed negative relationship between time in structured activities at age 4 and verbal fluency switching ability at age 7. The resulting model showed good fit $\left(\chi^{2}(65)=92.26, p=.015\right.$; CFI $=.946$; RMSEA $\left.=.022\right)$, with vocabulary positively predicting verbal fluency switching performance at each age, and showing a weak positive association with structured time participation at age 7. After controlling for vocabulary knowledge, children who spent more time in structured activities continued to show marginally worse verbal fluency switching ability at age $7\left(\beta=-.23 ; \chi_{\text {diff }}^{2}(1)=3.31 ; \mathrm{p}=.068\right)$. The positive cross-path between early verbal fluency performance and later structured activity participation also persisted $\left(\beta=.27 ; \chi_{\text {diff }}^{2}(1)=5.10 ; \mathrm{p}=.024\right)$, suggesting that early verbal fluency does not predict later structured activity participation simply because it is a proxy for vocabulary, which in turn predicts greater enrollment in structured activities early in childhood. These findings suggest that vocabulary development alone cannot explain observed links between structured activity participation and verbal fluency switching ability.

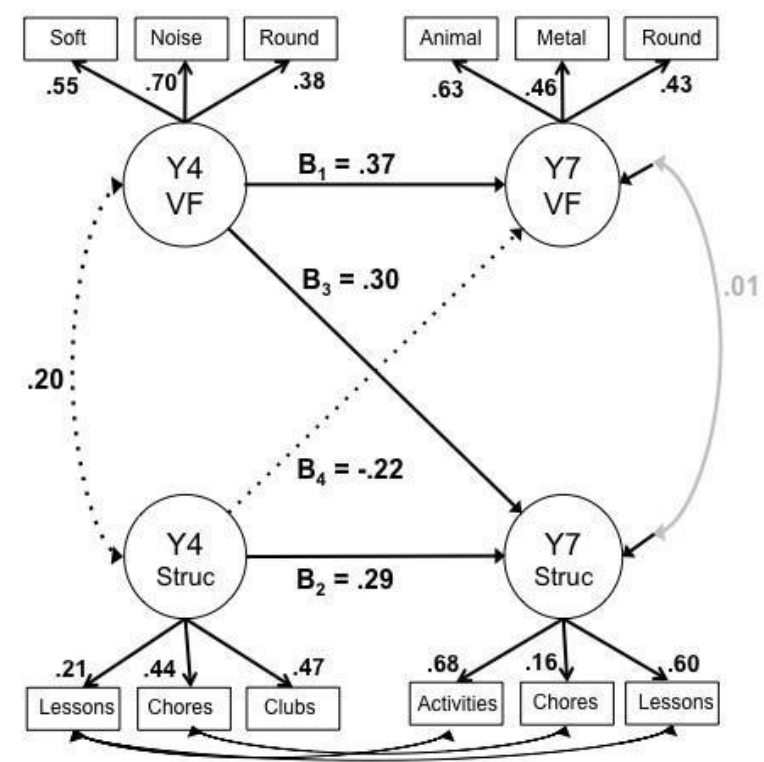


Figure 1: Phenotypic cross-lagged panel model relating structured activity participation and verbal fluency performance from age 4 to age 7 . Children who participated in more structured activities at age 4 showed marginally worse performance in verbal fluency at 7 , controlling for age 4 verbal fluency performance and concurrent structure time, as predicted. Children who showed better verbal fluency switching ability at age 4 spent more time in structured activities at age 7, controlling for age-4 structured activity participation and stability in verbal fluency switching ability from 4 to 7 . In all models, standardized parameters shown; trend-level paths are indicated by dashes; paths that do not meet statistical significance criteria are in gray. The model showed moderately good fit $\left(\chi^{2}(45)=62.95, \mathrm{p}=.039 ; \mathrm{CFI}=.941 ; \mathrm{RMSEA}=.021\right)$.

Similarly, controlling for SES did not alter paths between verbal fluency and structured activity participation. In a model including SES as a covariate loading on verbal fluency and structured activity participation at each age $\left(\chi^{2}(53)=76.49, p=.019 ;\right.$ CFI $=.930$; RMSEA $\left.=.022\right)$, cross-paths linking time use and verbal fluency were largely unaffected. Controlling for differences in SES, children who who participated in more structured activities at age 4 showed marginally worse performance in verbal fluency at age 7, controlling for earlier verbal fluency performance and year-7 structured time $\left(\beta=-.23 ; \chi_{\text {diff }}^{2}(1)=3.08 ; \mathrm{p}=.079\right)$. Similarly, children who demonstrated better verbal fluency performance at age 4 participated in more structured activities at age $7(\beta=.27$; $\left.\chi_{\text {diff }}^{2}(1)=5.06 ; \mathrm{p}=.025\right)$, accounting for earlier structured activity participation and contemporaneous verbal fluency ability.

\section{Relationships between structured activity participation and verbal fluency into adolescence}

As a final step, we extended the model to test whether time in structured activities at age 7 continued to predict verbal fluency switching performance at age 16 , controlling for temporal stability in each construct as in prior models (Figure 2). Because only two verbal fluency prompts and two measures of structured activity participation were collected at age 16 (chores and club participation), indicators for each construct were constrained to be equal. This constraint contributed to relatively poor overall fits across the base model and subsequent models testing for relationships with general cognitive ability, SES and vocabulary. No relationship between structured activity participation and verbal fluency switching ability emerged between year 7 and year 16 . Although this pattern is difficult to interpret given poor model fit, it could suggest that observed relationships are specific to younger children, that the relationship does not hold using more 
restricted measures of structured activity participation, or that 'structured' activities show varying levels of adult involvement across age, a topic we return to in the Discussion.

In sensitivity tests described in Supplemental Materials, we conducted two sets of analyses to test whether the relationship between verbal fluency and participation in structured activities was specific to switching ability, or could instead be explained by other factors that do not reflect children's ability to engage executive functions in self-directed contexts. To evaluate whether verbal fluency showed relationships with time use because it serves as a proxy for intelligence, we tested links between time use and verbal fluency persisted after controlling for $\mathrm{g}$, and found that they persisted. We next tested the possibility that verbal fluency simply acts as a proxy for vocabulary knowledge at each age, and found that structured activity participation at age 4 did not predict vocabulary at age-7. Similarly, early vocabulary did not significantly predict later structured activity participation, suggesting that observed links are not driven by aggregate changes in vocabulary.

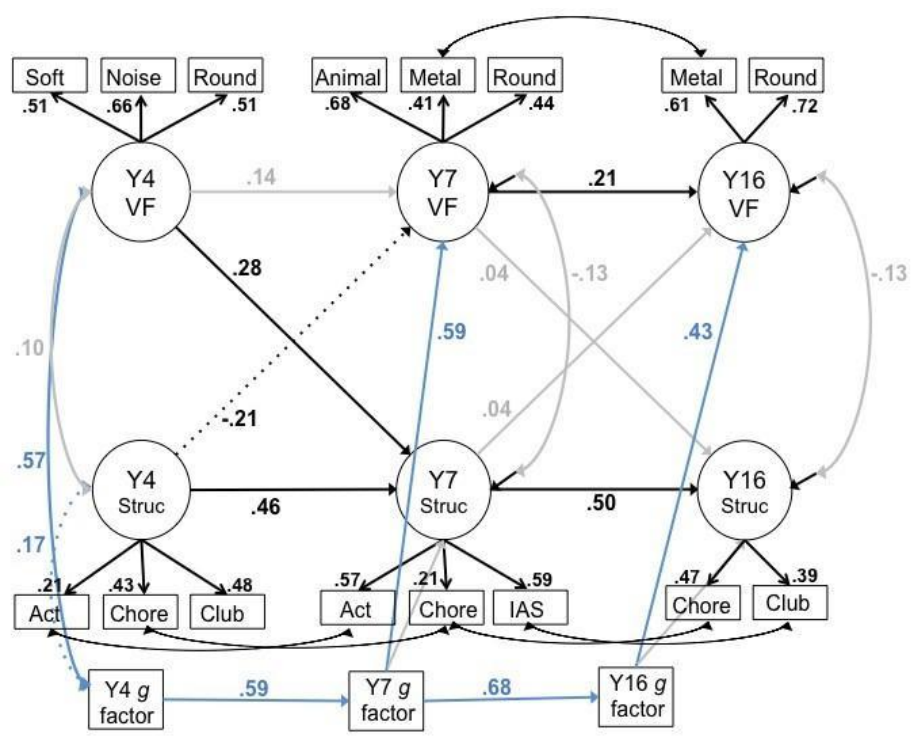

Figure 2: Verbal fluency switching ability and structured activity participation did not show similar relationships across year-7 and year-16, such that each construct did not predict the other. The model produced poor fit $\left(\chi^{2}(133)=236.60\right.$; $<<$ .0001 ; CFI $=.910$; RMSEA $=.029$ ), likely because unstandardized loadings for two-indicator factors were constrained at year-16. 


\section{Household structure and verbal fluency switching ability}

We next evaluated whether household-level indicators of structure from the Moos Family Environment Survey showed similar relationships with children's verbal fluency, such that early exposure to a structured family environment was associated with worse self-directed switching in verbal fluency at age 7 , and earlier verbal fluency ability predicted a more-structured environment at age-7. A cross-lagged panel model relating household structure and verbal fluency switching ability across ages 3 and 7 showed somewhat poor fit $\left(\chi^{2}(29)=49.15, p=.015\right.$; CFI = .938; RMSEA = .027; Figure 3).

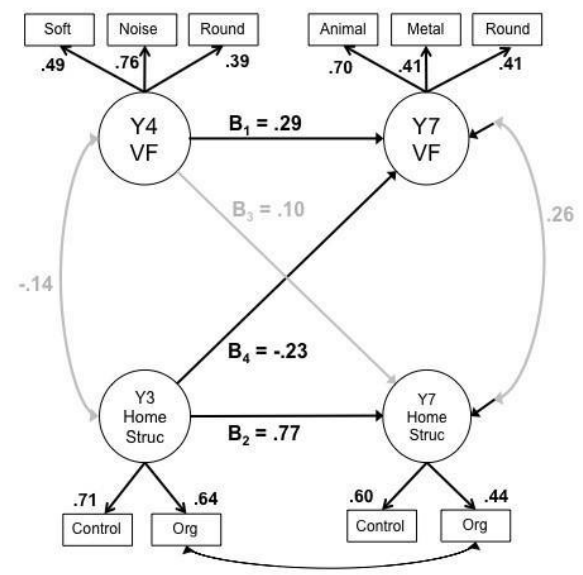

Figure 3: Children living in more structured household environments at age 3 showed worse verbal fluency switching performance at age 7, controlling for earlier verbal fluency ability and stability in household-level structure across time. The model showed somewhat poor fit, however, when loadings for household structure were constrained to equality: $\chi^{2}$ $(29)=49.15, p=.015 ; \mathrm{CFI}=.938$; RMSEA $=.027$.

Controlling for earlier verbal fluency and concurrent household structure, children whose parents reported high levels of household structure at age 3 showed worse verbal fluency switching ability at age $7\left(\beta=-.23 ; \chi_{\text {diff }}^{2}(1)=4.68 ; p=.031\right)$. Children's verbal fluency performance at age 4 did not predict household structure at age 7 (path $\mathrm{B}_{3} ; \chi_{\text {diff }}^{2}(1)=1.05 ; p>.3$ ), challenging the reverse causal inference that children with worse self-directed switching at age 3 were exposed to more 
environmental structure at age 7, as would be expected if parents modified the household environment to accommodate poorer levels of child self-direction.

Tests of SES and vocabulary as hidden variables. As before, we tested whether the observed relationship between earlier exposure to household structure and later verbal fluency performance persisted after controlling for two potential confounding variables, vocabulary and SES. In each model, household structure at age 4 continued to show a negative relationship with subsequent verbal fluency switching performance, controlling for earlier verbal fluency ability and simultaneous structured activity participation (Vocabulary-augmented model path $\mathrm{B}_{4}=-.22 ; \chi_{\text {diff }}^{2}(1)=4.46, \mathrm{p}=$ $.035 ; 3.8$; SES-augmented model path $\left.\mathrm{BB}_{4}=-.28 ; \chi_{\text {diff }}^{2}(1)=6.01, \mathrm{p}=.014\right)$. Additionally, as in the basic model relating household structure to verbal fluency switching performance, year-4 verbal fluency switching performance did not predict later household structure in either model, controlling for earlier structure and contemporaneous verbal fluency (ps > .3).

\section{Relationships between household structure and verbal fluency into adolescence}

Moos FES variables were only available for 346 twins at year 15, reducing power to detect effects. However, the relationship between household structure and later verbal fluency performance reversed from 7 to 15 , such that twins in households with higher levels of structure at age 7 showed better verbal fluency performance at age $16\left(\chi_{\text {diff }}^{2}(1)=4.08 ; p=.044\right)$. This path persisted in models controlling for general cognitive ability and SES.

\section{Development of Composite Model}

As a final step, we explored whether household structure and children's structured activity participation showed distinct relationships with verbal fluency switching ability, after controlling for their shared variance. This model demonstrated poor fit $\left(\chi^{2}(92)=126.62, p>.009\right.$; CFI = .917; RMSEA $=.021)$. Although household structure and child structured activity participation were positively associated at ages 3 and $4(\beta=.15 ; p=.013)$ and showed negative paths with year7 verbal fluency switching, neither path reached significance ( $p$ 's $>.3$ ). Modification indices suggested fit 
could be improved via correlations across family-level and twin-level structure factors, suggesting that these factors may capture different dimensions of a common construct (e.g., children's time in adult-structured environment). ${ }^{6}$

\section{Genetic Analyses: Examining the Etiology of Links between Structured Environments and Self-directed Switching in Verbal Fluency}

The longitudinal analyses in the preceding section are consistent with the hypothesis that time in more-structured environments causally affects children's ability to engage executive functions in self-directed contexts. Specifically, we found that twins who spent more time in structured environments at age 4 went on to show worse verbal fluency performance at age 7 . Unexpectedly, we also observed that twins who switched more frequently in verbal fluency at age 4 went on to participate in more structured activities at age 7, though this relationship did not emerge in tests linking earlier verbal fluency to later household structure. One explanation for the observed relationship is that children who show the ability to engage executive functions in self-directed contexts early in life are given more opportunities to participate in structured activities later in development, or are more likely to seek out such opportunities.

Critically, however, controlling for temporal precedence does not definitively rule out hidden variables that may confound interpretation of links between verbal fluency and environmental structure. One unexplored possibility is that observed links between environmental structure and self-directed switching ability in verbal fluency are driven by common genetic factors. If the same genetic factors that support developing self-directed EF also influence the structure of children's environments, hypothesized causal links between structured environments and verbal fluency switching ability could instead be driven by genetic mediation.

\footnotetext{
${ }^{6}$ This hypothesis could be tested via construction of formative, or latent composite (LC) variables at each time point composed of latent variables for household structure and structured activity participation. Because considerable debate remains over the interpretability of formative variables, particularly in their endogenous form (Bollen \& Diamantopoulos, 2017; Cadogan \& Lee, 2013), and questions of interpretability are further complicated in formative variables composed of latent variables, we have opted to present separate models for each construct.
} 
To test whether genetic factors simultaneously influenced children's verbal fluency ability and their time use, we used a cross-lagged genetic model to test for environmental mediation. In this model, variance decomposition isolates confounding influences so that the etiology of specific cross-lagged paths can be investigated. As in the standard cross-lagged panel design, genetic models adjust for shared variance across constructs at T1, the temporal stability of each construct between $\mathrm{T} 1$ and T2, and the reverse cross-lag (e.g., between earlier verbal fluency performance and later time use).

As a preliminary step, we generated common pathway models analyzing genetic, shared environmental, and nonshared environmental influences on verbal fluency switching ability and structured activity participation at ages 4 and 7. ACE models for verbal fluency switching ability show mixed genetic and environmental influences on abilities across time. At age 4, most variance was associated with the E component, representing strong effects of nonshared environment. Genetic and shared environmental factors also showed influence at age 4, though neither parameter met significance criteria. At age 7, unshared environmental and genetic factors influenced performance, though the A contribution only met significance criteria after the shared environmental (C) component was dropped from the model.

By contrast, structured activity latent variables showed no genetic influence (A) in year 7, and minimal, non-significant genetic influence at year 4. At each age, shared environmental variance contributed to structured activity performance. The influence of shared environmental factors is clear from comparison of $\mathrm{MZ}$ and $\mathrm{DZ}$ twin correlations, which illustrate this minimal genetic influence. MZ and DZ twins showed similar correlations in both years, and correlations were high overall. These findings suggest that structured activity participation is driven by environmental rather than genetic influences in early childhood, and are consistent with past studies of child time use (e.g. Fisher et al., 2010; Franks et al., 2005). 
Table 5: Genetic and Environmental (ACE) Contributions to Verbal Fluency Switching and Structured Time Participation at Ages 4 and 7.

\begin{tabular}{|c|c|c|c|c|}
\hline & $A_{c}$ & $\mathrm{C}_{\mathrm{c}}$ & $\mathrm{E}_{\mathrm{c}}$ & Model Fit \\
\hline \multicolumn{5}{|l|}{ Year 4} \\
\hline Verbal Fluency Switching & .29 & .52 & .80 & $\chi^{2}(36)=55.86, p=.018 ; \mathrm{CFI}=.812$ \\
\hline Structured Activities & .21 & .97 & .12 & $\chi^{2}(37)=43.59, p>.2 ; \mathrm{CFI}=.997$ \\
\hline \multicolumn{5}{|l|}{ Year 7} \\
\hline Verbal Fluency Switching & .85 & .16 & .50 & $\chi^{2}(47)=43.89, p=.602 ; \mathrm{CFI}=1.00$ \\
\hline Structured Activities & .00 & 1.00 & .09 & $\chi 2(37)=55.55, p=.026 ; \mathrm{CFI}=.990$ \\
\hline
\end{tabular}

Note: To improve fit, verbal fluency switching models were estimated with indicator-specific residuals instead of indicator-specific ACE estimates. Significant estimates (tested using difference tests) shown in bold.

We next tested the etiology of relationships between verbal fluency switching ability and structured time participation in two cross-lagged genetic models estimating individual contributions from ACE components via Cholesky decomposition. In a Cholesky decomposition, an observed variable is regressed on the latent variance components $(\mathrm{A}, \mathrm{C}$, and $\mathrm{E})$ of the variables preceding it. Thus, in Figure 4, A1, C1, and E1 explains the total variance in verbal fluency switching ability at year 4. Latent variables representing year-4 structured time, year-7 structured time, and year-7 verbal fluency ability are subsequently regressed on A1, C1, and E1. Latent variables A2, C2, and E2 thus explain residual variance in year-4 structured time that is not correlated with A1, C1, and E1. A2, C2, and E3 explain additional variance in year-7 structured time and year-7 verbal fluency ability that is uncorrelated with A1, C1, and E1, and A2, C2, and E2. In this way, shared ACE contributions to temporally-lagged variables can be investigated by reordering variables, such that the preceding variable is in position 2 , and the outcome variable is in position 4 .

Because the year-4 verbal fluency common path model showed relatively poor fit (Table 5), contributing to fit issues in the combined Cholesky decomposition, we fit genetic cross-lagged models to latent variable factor scores extracted at the phenotypic level. Figure 4 represents decomposition of the age-4 structured time to age-7 verbal fluency path; the corresponding model for the age-4 verbal fluency to age-7 structured time is shown in Figure 5. In each model, path loadings sum to denote relationships at the phenotypic level. For example, the contribution of 
combined A, C, and E sources of influence to the association between structured activity participation and verbal fluency at age 4 is equivalent to $\left(a_{11} * a_{12}\right)+\left(c_{11} * c_{12}\right)+\left(e_{11} * e_{12}\right)$. Thus, ACE estimates for the phenotypic cross-lag between year-4 structured activity participation and year-7 verbal fluency, controlling for contemporaneous correlation at age 4, stability in verbal fluency and structured time participation from 4 to 7 , and the reverse cross-lag, is equivalent to the sum of the products of ACE paths linking structured activity participation at 4 and verbal fluency switching performance at 7, via latent variables $A_{2} C_{2}$, and $E_{2}$. These paths sum to the phenotypic correlation, as follows: $\left(a_{22}=.14 * a_{24}=.03\right)+\left(c_{22}=.70 * c_{24}=.06\right)+\left(e_{22}=.24 * e_{24}=.43\right)=.15$.

As shown in Figure 4, the phenotypic cross-lag between year-4 structured activity participation and year-7 verbal fluency switching ability can be explained entirely by environmental contributions. Approximately 68 percent of the variance in the phenotypic cross-lag can be explained by the influence of nonshared environmental factors, as calculated by dividing the product of related path estimates by the phenotypic cross-lag: $\left(e_{22} * e_{24} /\left(a_{22} * a_{24}+c_{22} * c_{24}+e_{22} * e_{24}\right)\right.$, equivalent to $(.24 * .43) / .15$. The remainder of the phenotypic association is explained by shared environmental influence (though these paths do not reach significance), with additive genetic influences contributing $<1$ percent of the observed association. These results are consistent with our hypothesized causal links between structured environments and verbal fluency switching ability, and do not indicate that these links are instead driven by genetic mediation.

The corresponding cross-lag between year-4 verbal fluency performance and year-7 structured activity participation can also be explained by environmental rather than genetic influences (Figure 5). Approximately 69 percent of the variance in the phenotypic cross-lag can be explained by the influence of shared environmental factors, and 28 percent is attributable to non-shared environmental influences, with negligible contributions from genetic factors.

\section{Discussion}

Drawing on observations from a genetically-informative longitudinal twin sample, we demonstrate a causal association between children's early time in structured activities and 
structured household environments and later self-directed executive function, as indexed by verbal fluency performance. In independent analyses, children's structured activity participation and household ratings of structure at age 4 predicted worse verbal fluency performance at age 7 , controlling for earlier verbal fluency performance and concurrent structured time/household structure. These relationships persisted after controlling for multiple potentially confounding variables, including general cognitive ability, vocabulary, and a measure of socioeconomic status. Follow-up genetic analyses relating children's early time in structured activities to their later verbal fluency indicated that this relationship was mediated by nonshared environmental factors, consistent with the hypothesis that that early structured time causally affects later verbal fluency performance.

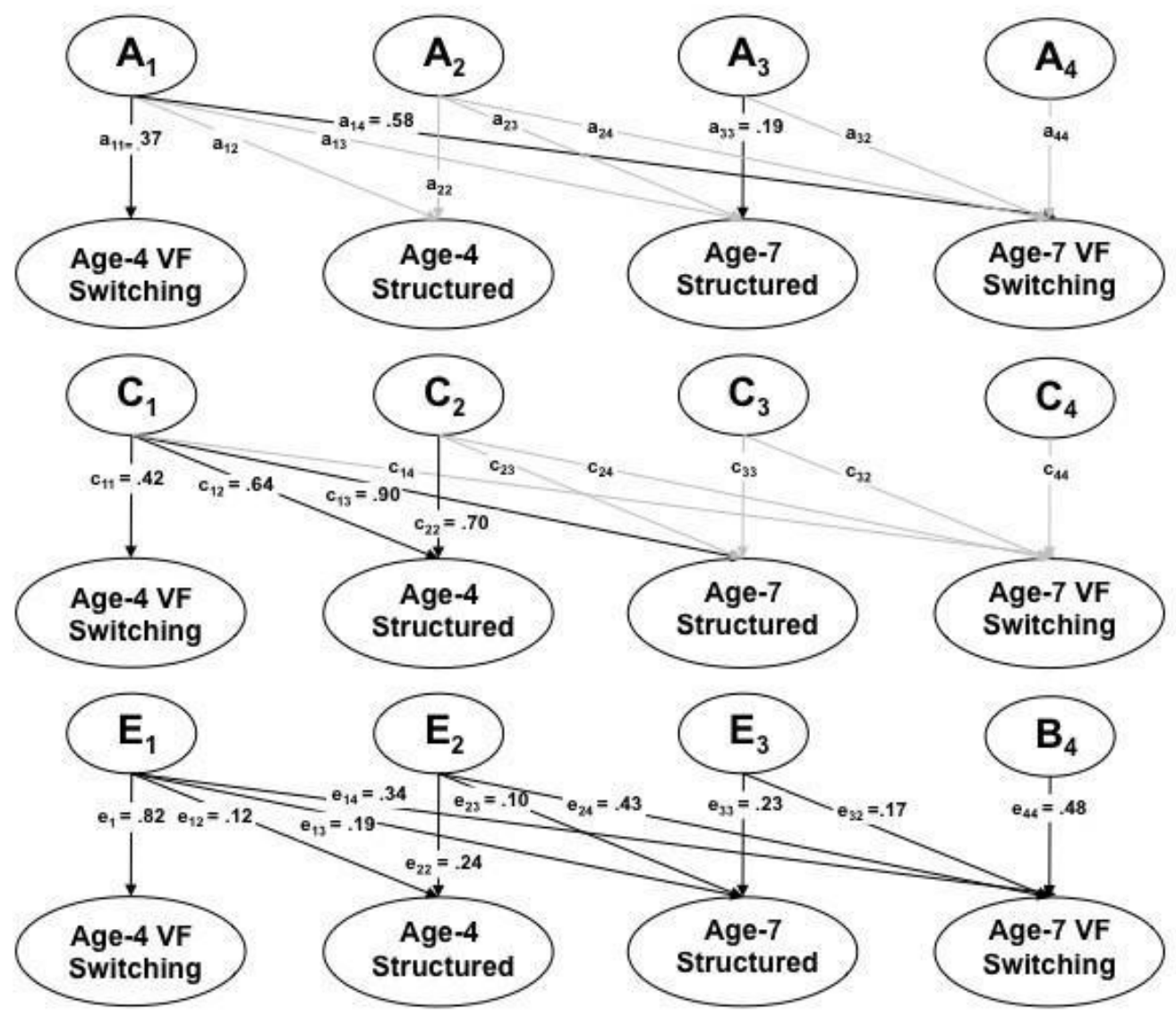

Figure 4: This model evaluates ACE contributions to the cross-lag from structured activity participation at age 4 to verbal fluency switching ability at age 7. Factor scores were used to evaluate relationships between verbal fluency performance and structured time (here represented as latent variables). Latent variables indicated contributions from A (additive genetic influences), C (shared environmental influences), and E (nonshared environmental influences). Path estimates are 
standardized; only one twin shown. Significance of mediating paths between year-4 structure and year-7 verbal fluency confirmed by difference tests; non-significant paths indicated in gray.

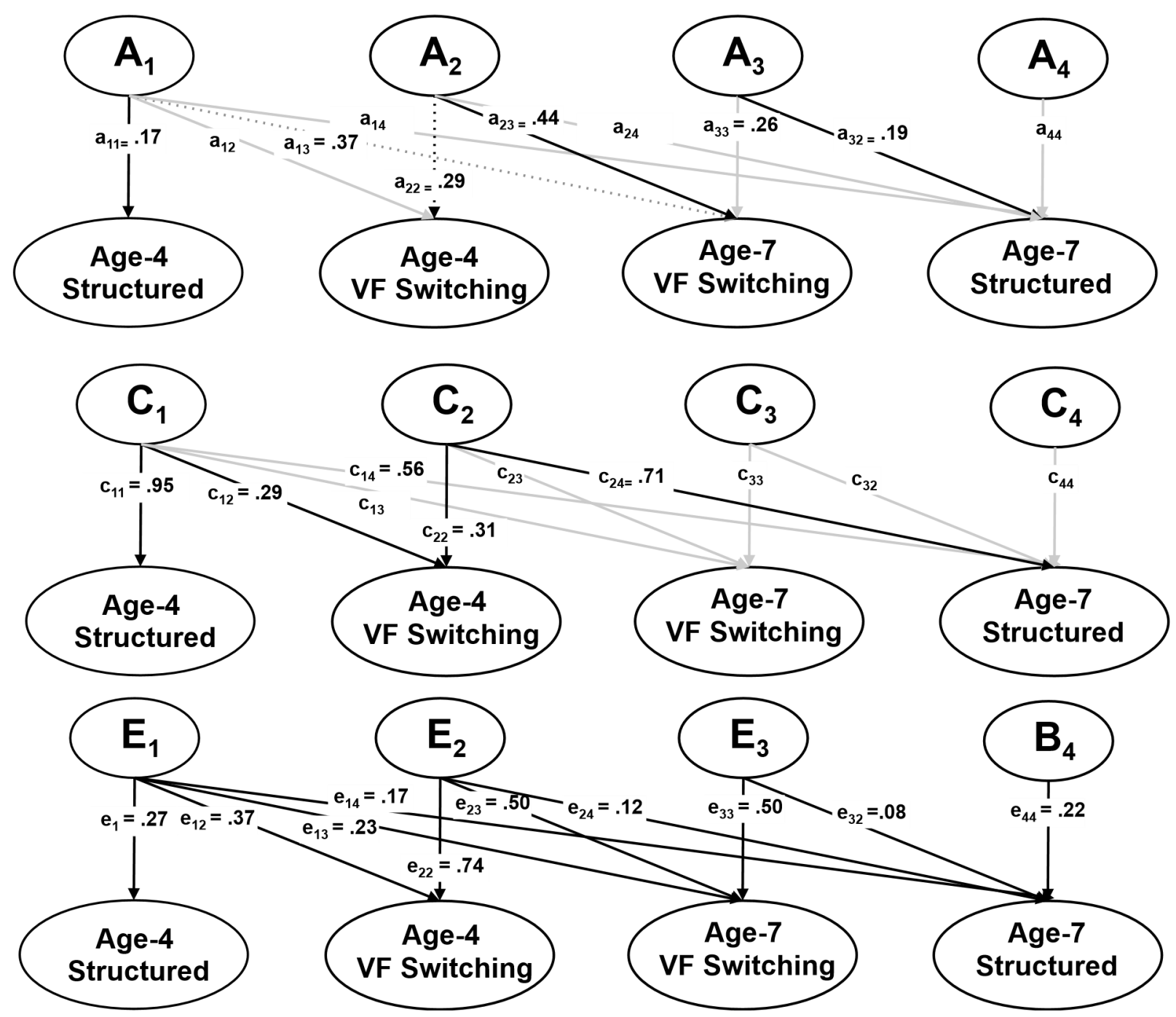

Figure 5: This model evaluates ACE contributions to the cross-lag from verbal fluency switching ability at age 4 to structured activity participation at age 7. Factor scores were used to evaluate relationships between verbal fluency performance and structured time (here represented as latent variables). Latent variables indicated contributions from $\mathrm{A}$ (additive genetic influences), C (shared environmental influences), and E (nonshared environmental influences). All path estimates are standardized; only one twin shown. Significance of mediating paths between year-4 verbal fluency and year-7 structure confirmed by difference tests; non-significant paths indicated in gray.

Unexpectedly, children who switched more often in verbal fluency at age 4 went on to participate in more structured activities at age 7. Although this relationship persisted in models controlling for SES, vocabulary, and general cognitive ability, it did not extend to our measure of environmental structure in the home. One explanation for this finding is that parent EF predicts both 
child EF and household structured activity preferences, resulting in a passive gene-environment correlation (e.g., parents pass on high EF to their children, and are also more likely to enroll their children in structured activities). This explanation is potentially supported by the significant shared environmental mediation (C) in the present model, which can indicate passive gene-environment mechanisms. The potential influence of such mechanisms could be investigated via alternative twin designs (e.g., Price \& Jaffee, 2008).

We also replicate and extend previous tests of genetic and environmental influence on children's early time use and self-directed executive function. At age 4, nonshared environmental factors and measurement error explained 64 percent of the variance in children's self-directed executive function, with no genetic effect on performance. Interestingly, Kave and colleagues (2013) found almost identical non-shared environmental effects on verbal fluency word production scores (63\%) in 4-year-old Israeli twins. By age 7, we find that verbal fluency shows a more adult-like etiology, with a stronger genetic contribution (72\%) and weaker nonshared environmental influence (25\%). By contrast, variance in structured activity participation was entirely explained by shared environmental factors at each age, with no genetic influence in year 7, and minimal, non-significant genetic influence at year 4 . These findings suggest that structured activity participation is driven by environmental rather than genetic influences in early childhood, and are consistent with past studies of child time use (e.g. Fisher et al., 2010; Franks et al., 2005).

Our findings also raise the possibility that verbal fluency tasks tap distinct cognitive processes across 4 and 7 year olds. In models controlling for general cognitive ability, the autoregressive path between year-4 and year-7 verbal fluency switching performance was attenuated, suggesting that covariance across these measures could be explained by general cognitive ability rather than individual differences in verbal fluency-specific processes. One interpretation of this finding is that 4-year-olds draw on distinct processes in verbal fluency, relative to 7-year-olds, and any remaining common variance across 4 and 7 can be attributed to general cognitive ability. To definitely test whether verbal fluency draws on distinct cognitive abilities across development, future tests could 
systematically explore other factors that might contribute to performance at 4 and observed links with structured time participation at 7 , including confidence and behavioral inhibition.

As in prior work, our conclusions about links between children's time use and their developing self-directed EF are limited by our available measures of time use. We have treated structured activity participation (i.e., the number of structured activities children participate in) as a proxy for 'time in structured activities', but some children in this study may have spent a great deal of time engaging in a single structured activity, while others spent very little time in multiple structured activities. These differences likely introduced noise in the present analyses. Studies measuring response-to-dosage (e.g., how time in specific structured activities relates to specific outcomes) could help to clarify how structured experiences relate to the ability to engage executive functions in self-directed contexts. Additionally, differences in factor structure across time driven by lack of measure availability may have attenuated effects, particularly in analyses relating year-16 to year-7. Additionally, because the present data set did not include reliable longitudinal measures of time in less-structured activities, we cannot rule out the possibility that observed relationships between structured activity participation and verbal fluency switching ability were driven by opportunity costs, such that time in structured activities reduced children's time in less-structured activities that are beneficial to verbal fluency switching performance.

More sensitive measures of time in structured activities could facilitate better analyses of how individual differences in experiences relate to developing verbal fluency ability. The present modeling approach estimates the rank order stability of children's verbal fluency switching ability and environmental structure over time. Although cross-lagged parameters in this model are often interpreted as between-individual effects of $X_{\mathrm{t}-1}$ on $Y_{\mathrm{t}}$, controlling for $Y_{\mathrm{t}-1}$, such descriptions are imprecise: observed estimates from cross-lagged panel models pool within-subject and between-subject effects (Berry \& Willoughby, 2017; Curran \& Bauer, 2011). Under optimal circumstances, such effects would be disaggregated. For example, one could test whether an increase in an individual child's typical level of structure (above her typical trend, or baseline structure) predicted a subsequent increase in her self-directed switching performance, after adjusting for 
earlier verbal fluency performance and time-invariant covariates. Although techniques to capture within-subject variation in observed variables have been developed (e.g., structured residual approaches), limitations in the present data set (ordinal variables, limited time points) prevent their use (Curran et al., 2014).

This study also raises the possibility that links between environmental structure and emerging self-direction may vary across development. Specifically, children living in more structured households at age 7 showed better verbal fluency performance at 16 , controlling for potential confounding factors such as SES and general cognitive ability. Although models including adolescent data showed relatively poor fit, complicating interpretation, one explanation for this finding is that structured environments begin to confer more benefits than costs in late middle childhood or early adolescence. This interpretation is consistent with a large body of work finding associations between structured leisure activity participation and several positive outcomes in older children and adolescents. For example, a study of $10^{\text {th }}$ graders found that student participation in academic clubs, religious activities, volunteer organizations, and sports teams was associated with better academic performance (Eccles \& Barber, 1999). These relationships persisted after controlling for verbal and quantitative skills. Some forms of adolescent structured activity participation have also been linked to improved emotional well-being (Bohnert et al., 2008; Fredricks \& Eccles, 2008) and decreased substance abuse (Eccles \& Barber, 1999). Thus, adolescent participation in structured leisure activities benefits factors that protect against typical patterns of academic decline in adolescence, such as confidence or the desire to achieve status among similarly-inclined peers. Interestingly, unstructured leisure time predicts several negative outcomes in adolescence, including delinquency and low classroom engagement (Osgood et al., 2005). Unstructured leisure time may provide adolescents more time to engage in risk-seeking behaviors, highlighting the possibility that links between time use and emerging self-direction may vary across development. A second explanation is that 'structured' activities vary in relative levels of adult-structured time across development, such that 'structured' activities for older children and adolescents offer more opportunities for self-direction than similar such activities for younger children. Whereas adults play a central role in 
structuring organizational meetings and lessons for younger children, adolescents and older children may take on an increasingly central role in structuring organizational meetings and lessons. If relative levels of structure vary with age, broad classifications of time use may be particularly misleading in longitudinal samples, obscuring true relationships between environmental structure and emerging self-direction.

Our findings are consistent with a causal role for structured time on developing EF, and suggest that observed links are driven by shared environmental rather than genetic factors. An important direction for future work is to develop experimental designs that manipulate children's exposure to environmental structure, to definitively test causal relationships between structured experiences and self-directed executive function. This work could also help to distinguish whether observed relationships are driven by opportunity costs to time in less-structured activities.

\section{Conclusion}

Historical shifts in child time use have inspired broad, societal questions about how environmental structure might affect children's self-directed behavior. Modern children may have fewer opportunities to engage in child-directed activities (determining on their own what they will do, and how they will do it) than their predecessors. Growing societal emphasis on early skill acquisition and heightened parental vigilance have contributed to reductions in the time children spend in unsupervised activities, including independent travel and play (Clements, 2004; Mullan, 2019). Activities such as outdoor play have increasingly been replaced by media activities, including video game play, computing, and television watching (Bavelier et al., 2010; Johnson, 2010; Vandewater et al., 2007), which typically offer fewer opportunities for child decision-making than other forms of leisure. Children also spend more time in structured, adult-led activities (Hofferth \& Sandberg, 2001a; Larson, 2001). Longitudinal studies of child time use and developing EF offer one way of testing how shifts in time use might affect children's goal-directed behavior. Our findings with this approach suggest that structured environments lead to worse self-directed executive function in children. Future investigations would benefit from exploration of relationships across societies and cultures, using controlled, cross-sectional comparisons. Better understanding of the sensitivity of 
self-directed EF to specific childhood experiences may ultimately inform, extend, and improve extant EF-focused interventions across the lifespan. 


\section{Supplemental Materials}

\section{A. Specificity of relationships between structured activity participation and verbal fluency switching performance}

We conducted two sets of analyses to test whether the relationship between verbal fluency and participation in structured activities was specific to switching ability, or could instead be explained by other factors that do not reflect children's ability to engage executive functions in self-directed contexts.

As an initial test, we examined whether the negative relationship between early structured activity participation and later verbal fluency switching ability persisted after controlling for general cognitive ability, or $g$-factor, at each age. General cognitive ability showed a strong positive association with verbal fluency switching performance and effectively eliminated the verbal fluency autoregressive path between ages 4 and $7\left(\chi_{\text {diff }}^{2}(1)=2.61 ; p=.106\right.$; Figure A1). This finding suggests that stability in verbal fluency performance across early childhood at least partially reflects individual differences in general cognitive ability, insomuch that g-factor accounts for all common variance across year-4 and year-7 verbal fluency. However, relationships between time use and verbal fluency persisted after controlling for $g$, ruling out the possibility that verbal fluency relates to time use because it is a proxy for intelligence. Controlling for g-factor at each age, early structured activity participation continued to show a negative association with later verbal fluency performance (path $\mathrm{B}_{4} r=-.22 ; \chi_{\text {diff }}^{2}(1)=3.25 ; \mathrm{p}=.071$ ), and early verbal fluency ability continued to positively predict later structured time participation $\left(\beta=.30 ; \chi_{\text {diff }}^{2}(1)=5.33 ; \mathrm{p}=.021\right)$. 


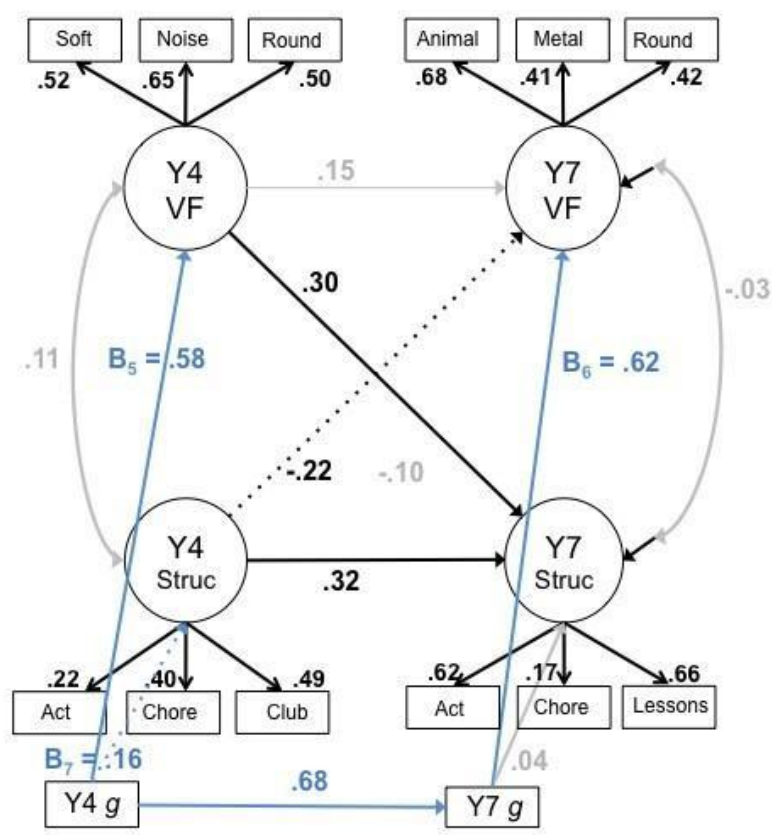

Figure A1: Controlling for general cognitive ability did not attenuate cross-lagged paths between verbal fluency switching performance and structured activity participation. The model showed moderately good fit $\left(\chi^{2}(65)=89.13, p=.025 ; \mathrm{CFI}=\right.$ $.964 ;$ RMSEA = .020).

Vocabulary. Children with better vocabulary knowledge typically produce more words in verbal fluency. Although we have attempted to control for differences in total word production by weighting switching measures to reduce bias from large clusters, it is possible that it is easier to detect switching ability in young children who know more words. If this is the case, replacing verbal fluency switching indices with an indicator of vocabulary performance should yield similar negative relationships between early time in structured activities and later vocabulary. To test the possibility that verbal fluency simply acted as a proxy for vocabulary knowledge at each age, we ran an additional cross-lagged panel model substituting verbal fluency factors with vocabulary performance at ages 4 and 7 (Figure A2). Structured activity participation at age 4 did not predict vocabulary at age-7 $\left(\beta=.08, \chi_{\text {diff }}^{2 \mathrm{SB}}(1)=1.42, p>.2\right)$, and early vocabulary did not significantly predict later structured activity participation $\left(\beta=.08, \chi_{\text {diff }}^{2 \mathrm{SB}}(1)=2.04, p=.153\right)$ suggesting that observed links are not driven by aggregate changes in vocabulary. 


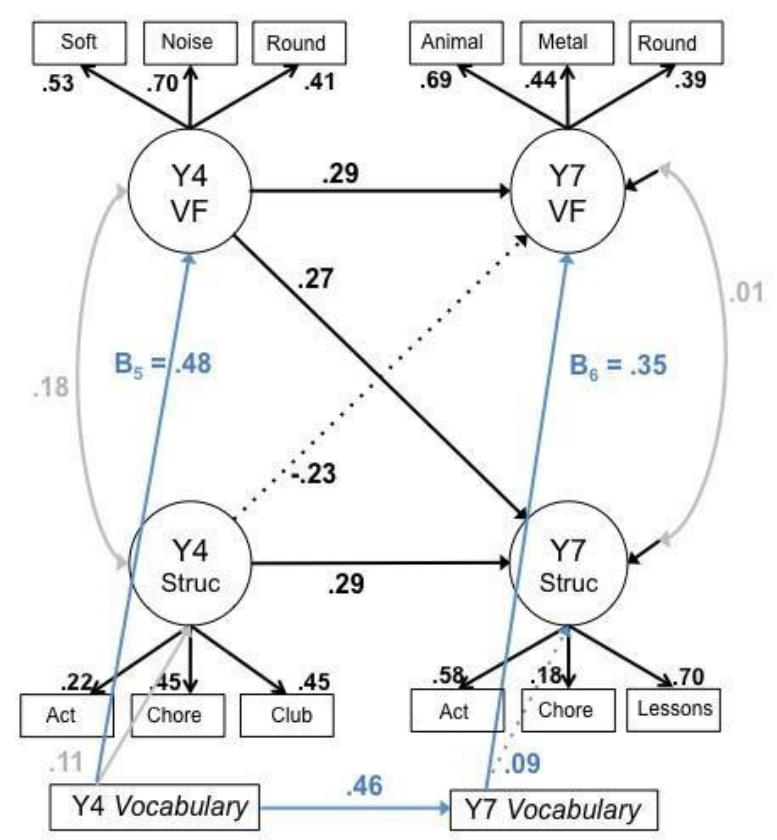

Figure A2: Controlling for vocabulary did not attenuate cross-lagged paths between verbal fluency switching performance and structured activity participation. The model showed moderately good fit $\left(\chi^{2}(65)=92.26, p=.015 ; \mathrm{CFI}=.946 ; \mathrm{RMSEA}=\right.$ $.022)$.

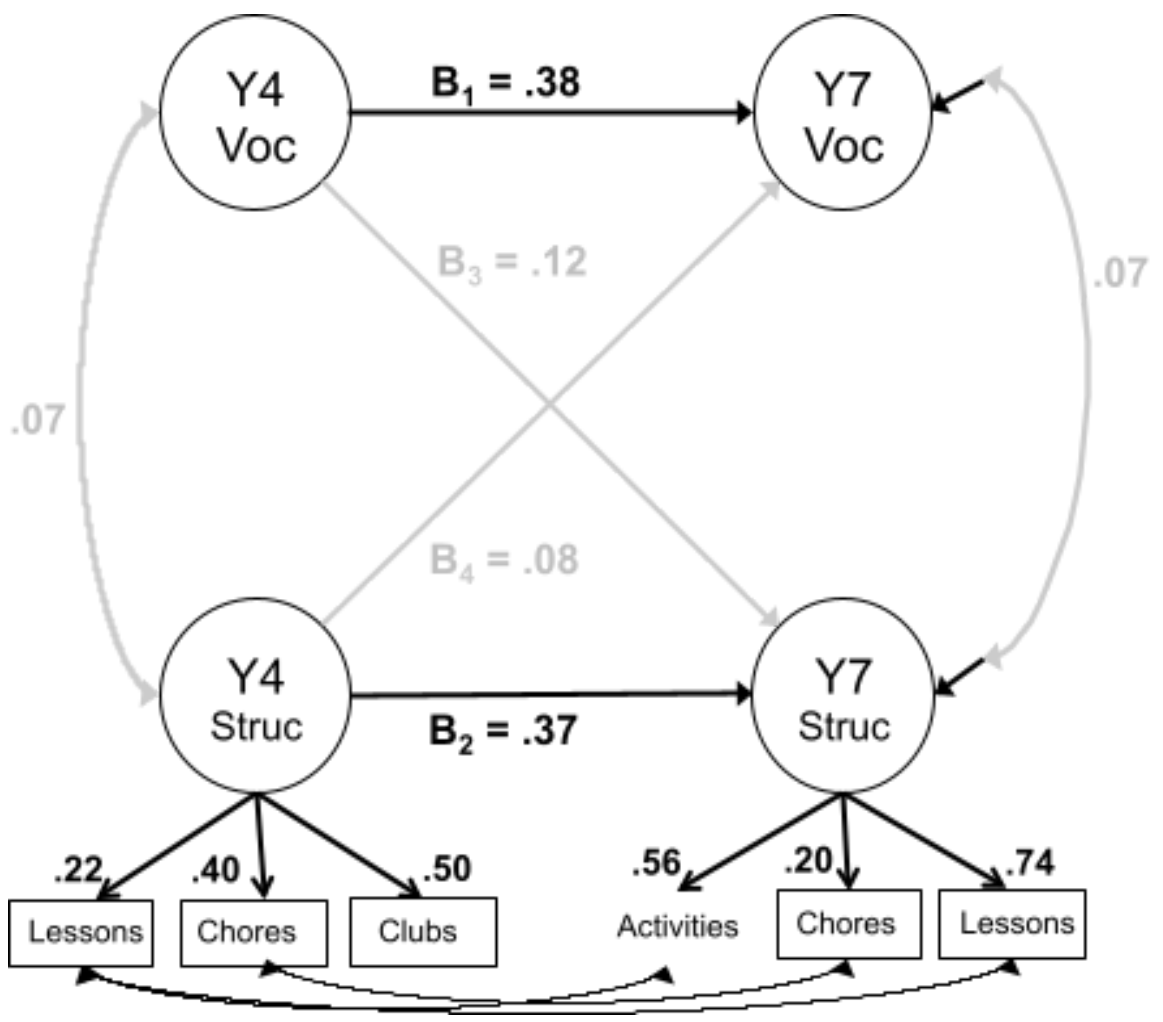


Figure A3: Child vocabulary and structured time participation show temporal stability, but levels of each construct at year- 4 do not predict outcomes at year-7. Model fit was excellent $\left(\chi^{2}(13)=\right.$

19.36, $\mathrm{p}=.112$; CFI = .972; RMSEA = .024).

structured activity participation at year-7 $\left(\beta=.27, \chi_{\text {diff }}^{2 \mathrm{SB}}(1)=4.96, p=.026\right)$, the negative path linking structured time to cluster size at year-7 did not meet significant criteria $\left(\beta=-.31, \chi_{\text {diff }}^{\text {2SB }}(1)=\right.$ $2.56, p=.110)$.

\section{B. Specificity of relationships between household structure and verbal fluency switching performance}

To test for specificity of relationships between household structure to self-directed switching indices, we evaluated whether relationships persisted in models controlling for general cognitive ability. Children exposed to more household structure at age 3 continued to generate fewer switches in verbal fluency at age 7 in models controlling for $g$ at each age (path $\mathrm{B}_{4}=-.23 ; \chi_{\text {diff }}^{2}(1)=5.60 ; p>$ .018, Figure A4). As a follow-up analysis, we again substituted verbal fluency switching ability for vocabulary performance at ages 4 and 7 . Although this model demonstrated good fit $\left(\chi^{2}(6)=11.06, p\right.$ $=.087 ; \mathrm{CFI}=.980 ; \mathrm{RMSEA}=.031$ ), neither cross-lagged path met significance criteria, indicating that earlier levels of vocabulary did not predict later household structure, and vice versa ( $p$ 's > .3). 


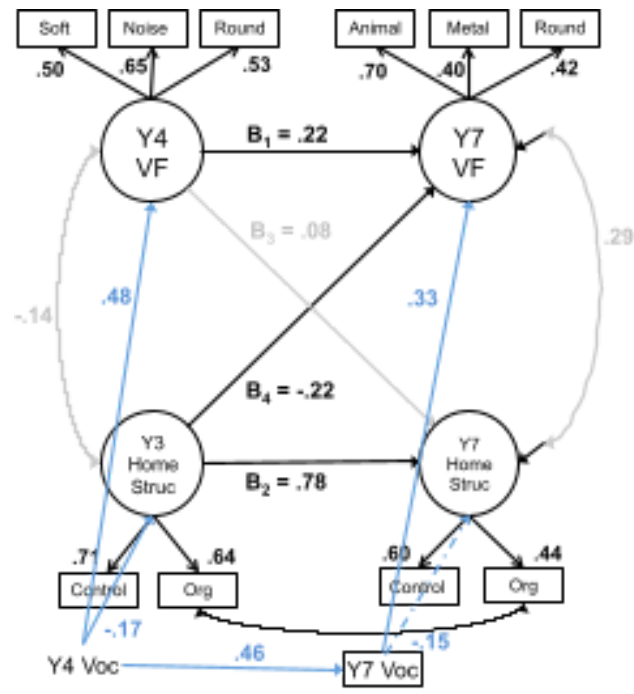

Figure A5: The relationship between children's earlier household structure and their later verbal fluency switching ability persisted after controlling for vocabulary at each age (path B4), though this model showed only moderately good fit $\left(\chi^{2}(48)=87.02, p>.001\right.$; CFI $=.920$; RMSEA $\left.=.030\right)$.

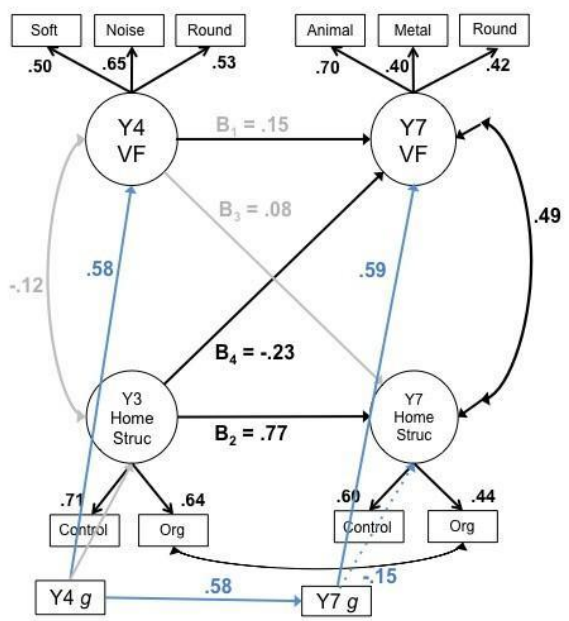

Figure A6: Cross-lagged panel model relating household structure to verbal fluency switching ability, ages 3-4 and 7, controlling for general cognitive ability at each age. 


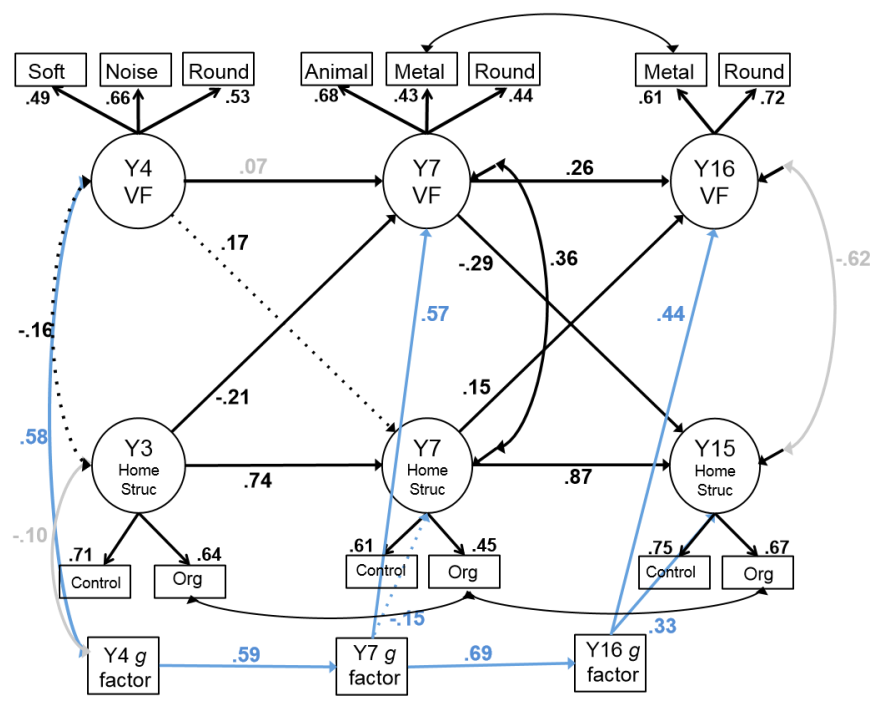

Figure A8: Cross-lagged panel model relating household structure to verbal fluency switching ability, ages 3-4, 7, and 15-16. 


\section{References}

Aaltonen, S., Ortega-Alonso, A., Kujala, U. M., \& Kaprio, J. (2010). A longitudinal study on genetic and environmental influences on leisure time physical activity in the Finnish twin cohort. Twin Research and Human Genetics, 13(5), 475-481. https://doi.org/10.1375/twin.13.5.475

Abwender, D. A., Swan, J. G., Bowerman, J. T., \& Connolly, S. W. (2001). Qualitative analysis of verbal fluency output: Review and comparison of several scoring methods. Assessment, 8(3), 323-338.

Achenbach, T. M., \& Edelbrock, C. S. (1983). Manual for the child behavior checklist: And revised child behavior profile. University of Vermont, Department of Psychiatry.

Ardila, A., Rosselli, M., Matute, E., \& Guajardo, S. (2005). The influence of the parents' educational level on the development of executive functions. Developmental Neuropsychology, 28(1), 539-560. https://doi.org/10.1207/s15326942dn2801_5

Barker, J. E., \& Munakata, Y. (2015). Developing self-directed executive functioning: Recent findings and future directions. Mind, Brain, and Education, 9(2), 92-99. https://doi.org/10.1111/mbe.12071

Barker, J. E., Semenov, A. D., Michaelson, L., Provan, L. S., Snyder, H. R., \& Munakata, Y. (2014). Less-structured time in children's daily lives predicts self-directed executive functioning. Frontiers in Psychology, 5. https://doi.org/10.3389/fpsyg.2014.00593

Bavelier, D., Green, C. S., \& Dye, M. W. G. (2010). Children, wired: For better and for worse. Neuron, 67(5), 692-701. https://doi.org/10.1016/j.neuron.2010.08.035

Bechtoldt, H. P., Benton, A. L., \& Fogel, M. L. (1962). An application of factor analysis in neuropsychology. The Psychological Record, 12, 147-156.

Berry, D., \& Willoughby, M. T. (2017). On the practical interpretability of cross-lagged panel models: Rethinking a developmental workhorse. Child Development, 88(4), 1186-1206. 
https://doi.org/10.1111/cdev.12660

Best, J. R., Miller, P. H., \& Naglieri, J. A. (2011). Relations between executive function and academic achievement from ages 5 to 17 in a large, representative national sample. Learning and Individual Differences, 21(4), 327-336. https://doi.org/10.1016/j.lindif.2011.01.007

Blair, C. (2017). Educating executive function. WIREs Cognitive Science, 8(1-2), e1403. https://doi.org/10.1002/wcs.1403

Blair, C., \& Razza, R. P. (2007). Relating effortful control, executive function, and false belief understanding to emerging math and literacy ability in kindergarten. Child Development, 78(2), 647-663. https://doi.org/10.1111/j.1467-8624.2007.01019.x

Bohnert, A. M., Kane, P., \& Garber, J. (2008). Organized activity participation and internalizing and externalizing symptoms: Reciprocal relations during adolescence. Journal of Youth and Adolescence, 37(2), 239-250. https://doi.org/10.1007/s10964-007-9195-1

Cameron, C. E., Brock, L. L., Murrah, W. M., Bell, L. H., Worzalla, S. L., Grissmer, D., \& Morrison, F. J. (2012). Fine motor skills and executive function both contribute to kindergarten achievement. Child Development, 83(4), 1229-1244. https://doi.org/10.1111/j.1467-8624.2012.01768.x

Clements, R. (2004). An investigation of the status of outdoor play. Contemporary Issues in Early Childhood, 5(1), 68-80. https://doi.org/10.2304/ciec.2004.5.1.10

Curran, P. J., \& Bauer, D. J. (2011). The disaggregation of within-person and between-person effects in longitudinal models of change. Annual Review of Psychology, 62(1), 583-619. https://doi.org/10.1146/annurev.psych.093008.100356

Curran, P. J., Howard, A. L., Bainter, S. A., Lane, S. T., \& McGinley, J. S. (2014). The separation of between-person and within-person components of individual change over time: A latent curve model with structured residuals. Journal of Consulting and Clinical Psychology, 82(5), 879-894. https://doi.org/10.1037/a0035297 
Diamond, A., \& Lee, K. (2011). Interventions shown to aid executive function development in children 4-12 years old. Science (New York, N.Y.), 333(6045), 959-964. https://doi.org/10.1126/science.1204529

Diamond, A., \& Ling, D. S. (2016). Conclusions about interventions, programs, and approaches for improving executive functions that appear justified and those that, despite much hype, do not. Developmental Cognitive Neuroscience, 18, 34-48. https://doi.org/10.1016/j.dcn.2015.11.005

Eccles, J. S., \& Barber, B. L. (1999). Student council, volunteering, basketball, or marching band: What kind of extracurricular involvement matters? Journal of Adolescent Research, 14(1), 10-43. https://doi.org/10.1177/0743558499141003

Engelhardt, L. E., Briley, D. A., Mann, F. D., Harden, K. P., \& Tucker-Drob, E. M. (2015). Genes unite executive functions in childhood. Psychological Science, 26(8), 1151-1163. https://doi.org/10.1177/0956797615577209

Fisher, A., van Jaarsveld, C. H. M., Llewellyn, C. H., \& Wardle, J. (2010). Environmental influences on children's physical activity: Quantitative estimates using a twin design. PloS One, 5(4), e10110. https://doi.org/10.1371/journal.pone.0010110

Fletcher, A. C., Nickerson, P., \& Wright, K. L. (2003). Structured leisure activities in middle childhood: Links to well-being. Journal of Community Psychology, 31(6), 641-659. https://doi.org/10.1002/jcop.10075

Franks, P. W., Ravussin, E., Hanson, R. L., Harper, I. T., Allison, D. B., Knowler, W. C., Tataranni, P. A., \& Salbe, A. D. (2005). Habitual physical activity in children: The role of genes and the environment. The American Journal of Clinical Nutrition, 82(4), 901-908. https://doi.org/10.1093/ajcn/82.4.901

Fredricks, J. A., \& Eccles, J. S. (2008). Participation in extracurricular activities in the middle school years: Are there developmental benefits for African American and European American 
youth? Journal of Youth and Adolescence, 37(9), 1029-1043.

https://doi.org/10.1007/s10964-008-9309-4

Friedman, N. P., Miyake, A., Altamirano, L. J., Corley, R. P., Young, S. E., Rhea, S. A., \& Hewitt, J. K. (2016). Stability and change in executive function abilities from late adolescence to early adulthood: A longitudinal twin study. Developmental Psychology, 52(2), 326-340. https://doi.org/10.1037/dev0000075

Friedman, N. P., Miyake, A., Young, S. E., Defries, J. C., Corley, R. P., \& Hewitt, J. K. (2008). Individual differences in executive functions are almost entirely genetic in origin. Journal of Experimental Psychology. General, 137(2), 201-225.

Gathercole, S. E., Pickering, S. J., Ambridge, B., \& Wearing, H. (2004). The structure of working memory from 4 to 15 years of age. Developmental Psychology, 40(2), 177-190. https://doi.org/10.1037/0012-1649.40.2.177

Gustavson, D. E., Panizzon, M. S., Elman, J. A., Franz, C. E., Beck, A., Reynolds, C. A., Jacobson, K. C., Xian, H., Toomey, R., Lyons, M. J., \& Kremen, W. S. (2018). Genetic and environmental influences on verbal fluency in middle age: A longitudinal twin study. Behavior Genetics, 48(5), 361-373. https://doi.org/10.1007/s10519-018-9910-6

Hauser, R. M., \& Featherman, D. L. (1977). The process of stratification: Trends and analyses. Academic Press.

Hayiou-Thomas, M. E., Kovas, Y., Harlaar, N., Plomin, R., Bishop, D. V. M., \& Dale, P. S. (2006). Common aetiology for diverse language skills in 4 1/2-year-old twins. Journal of Child Language, 33(2), 339-368. https://doi.org/10.1017/s0305000906007331

Hofferth, S. L., \& Sandberg, J. F. (2001a). Changes in American children’s time, 1981-1997. Advances in Life Course Research, 6, 193-229. https://doi.org/10.1016/S1040-2608(01)80011-3

Hofferth, S. L., \& Sandberg, J. F. (2001b). How American children spend their time. Journal of Marriage and Family, 63(2), 295-308. https://doi.org/10.1111/j.1741-3737.2001.00295.x 
Hu, L., \& Bentler, P. M. (1999). Cutoff criteria for fit indexes in covariance structure analysis: Conventional criteria versus new alternatives. Structural Equation Modeling, 6(1), 1-55. https://doi.org/10.1080/10705519909540118

Hurks, P. P. M., Schrans, D., Meijs, C., Wassenberg, R., Feron, F. J. M., \& Jolles, J. (2010). Developmental changes in semantic verbal fluency: Analyses of word productivity as a function of time, clustering, and switching. Child Neuropsychology: A Journal on Normal and Abnormal Development in Childhood and Adolescence, 16(4), 366-387. https://doi.org/10.1080/09297041003671184

Johnson, G. M. (2010). Young children's internet use at home and school: Patterns and profiles. Journal of Early Childhood Research, 8(3), 282-293. https://doi.org/10.1177/1476718X10379783

Jones-Odeh, E., Yonova-Doing, E., Bloch, E., Williams, K. M., Steves, C. J., \& Hammond, C. J. (2016). The correlation between cognitive performance and retinal nerve fibre layer thickness is largely explained by genetic factors. Scientific Reports, 6(1), 34116. https://doi.org/10.1038/srep34116

Kassai, R., Futo, J., Demetrovics, Z., \& Takacs, Z. K. (2019). A meta-analysis of the experimental evidence on the near- and far-transfer effects among children's executive function skills. Psychological Bulletin, 145(2), 165-188. https://doi.org/10.1037/bul0000180

Kavé, G., Eyal, N., Shorek, A., \& Cohen-Mansfield, J. (2008). Multilingualism and cognitive state in the oldest old. Psychology and Aging, 23(1), 70-78. https://doi.org/10.1037/0882-7974.23.1.70

Kave, G., Kigel, S., \& Kochva, R. (2008). Switching and clustering in verbal fluency tasks throughout childhood. Journal of Clinical and Experimental Neuropsychology, 30(3), 349-359. https://doi.org/10.1080/13803390701416197

Kavé, G., Shalmon, M., \& Knafo, A. (2013). Environmental contributions to preschoolers' semantic fluency. Developmental Science, 16(1), 124-135. https://doi.org/10.1111/desc.12010 
Kenny, D. A. (1975). Cross-lagged panel correlation: A test for spuriousness. Psychological Bulletin, 82(6), 887-903. https://doi.org/10.1037/0033-2909.82.6.887

Kent, J., \& Plomin, R. (1987). Testing specific cognitive abilities by telephone and mail. Intelligence, 11(4), 391-400.

Klenberg, L., Korkman, M., \& Lahti-Nuuttila, P. (2001). Differential development of attention and executive functions in 3- to 12-year-old finnish children. Developmental Neuropsychology, 20(1), 407-428. https://doi.org/10.1207/S15326942DN2001_6

Koren, R., Kofman, O., \& Berger, A. (2005). Analysis of word clustering in verbal fluency of school-aged children. Archives of Clinical Neuropsychology, 20(8), 1087-1104. https://doi.org/10.1016/j.acn.2005.06.012

Kovas, Y., Harlaar, N., Petrill, S. A., \& Plomin, R. (2005). “Generalist genes” and mathematics in 7-year-old twins. Intelligence, 33(5), 473-489. https://doi.org/10.1016/j.intell.2005.05.002

Lanting, S., Haugrud, N., \& Crossley, M. (2009). The effect of age and sex on clustering and switching during speeded verbal fluency tasks. Journal of the International Neuropsychological Society: JINS, 15(2), 196-204. https://doi.org/10.1017/S1355617709090237

Larson, R. W. (2001). How U.S. children and adolescents spend time: What it does (and doesn't) tell us about their development. Current Directions in Psychological Science, 10(5), 160-164. https://doi.org/10.1111/1467-8721.00139

Lawler, J. M., Esposito, E. A., Doyle, C. M., \& Gunnar, M. R. (2019). A preliminary, randomized-controlled trial of mindfulness and game-based executive function trainings to promote self-regulation in internationally-adopted children. Development and Psychopathology, 31(4), 1513-1525. https://doi.org/10.1017/S0954579418001190

Luo, Y. L. L., Haworth, C. M. A., \& Plomin, R. (2010). A novel approach to genetic and environmental analysis of cross-lagged associations over time: The cross-lagged relationship between self-perceived abilities and school achievement is mediated by genes as well as the 
environment. Twin Research and Human Genetics: The Official Journal of the International Society for Twin Studies, 13(5), 426-436. https://doi.org/10.1375/twin.13.5.426

Mahoney, J. L., \& Stattin, H. (2000). Leisure activities and adolescent antisocial behavior: The role of structure and social context. Journal of Adolescence, 23(2), 113-127. https://doi.org/10.1006/jado.2000.0302

Matute, E., Rosselli, M., Ardila, A., \& Morales, G. (2004). Verbal and nonverbal fluency in spanish-speaking children. Developmental Neuropsychology, 26(2), 647-660. https://doi.org/10.1207/s15326942dn2602_7

McAuley, T., Christ, S. E., \& White, D. A. (2011). Mapping the development of response inhibition in young children using a modified day-night task. Developmental Neuropsychology, 36(5), 539-551. https://doi.org/10.1080/87565641.2010.549871

Meeks, C. B., \& Mauldin, T. (1990). Children's time in structured and unstructured leisure activities. Lifestyles, 11(3), 257-281. https://doi.org/10.1007/BF00987003

Melby-Lervåg, M., Redick, T. S., \& Hulme, C. (2016). Working memory training does not improve performance on measures of intelligence or other measures of "far transfer": Evidence from a meta-analytic review. Perspectives on Psychological Science, 11(4), 512-534. https://doi.org/10.1177/1745691616635612

Miller, M. R., Müller, U., Giesbrecht, G. F., Carpendale, J. I., \& Kerns, K. A. (2013). The contribution of executive function and social understanding to preschoolers' letter and math skills. Cognitive Development, 28(4), 331-349. https://doi.org/10.1016/j.cogdev.2012.10.005

Miyake, A., \& Friedman, N. P. (2012). The nature and organization of individual differences in executive functions: Four general conclusions. Current Directions in Psychological Science, 21(1), 8-14.

Miyake, A., Friedman, N. P., Emerson, M. J., Witzki, A. H., Howerter, A., \& Wager, T. D. (2000). The unity and diversity of executive functions and their contributions to complex "Frontal Lobe" 
tasks: A latent variable analysis. Cognitive Psychology, 41, 49-100.

Moffitt, T. E., Arseneault, L., Belsky, D., Dickson, N., Hancox, R. J., Harrington, H., Houts, R., Poulton, R., Roberts, B. W., Ross, S., Sears, M. R., Thomson, W. M., \& Caspi, A. (2011). A gradient of childhood self-control predicts health, wealth, and public safety. Proceedings of the National Academy of Sciences of the United States of America, 108.

http://www.ncbi.nlm.nih.gov/pubmed/21262822

Mullan, K. (2019). A child's day: Trends in time use in the UK from 1975 to 2015. The British Journal of Sociology, 70(3), 997-1024. https://doi.org/10.1111/1468-4446.12369

Munakata, Y., Snyder, H. R., \& Chatham, C. H. (2012). Developing cognitive control: Three key transitions. Current Directions in Psychological Science, 21(2), 71-77.

Muthén, L. K., \& Muthén, B. O. (2012). Mplus (Seventh Edition) [Computer software]. Muthén \& Muthén.

Nichols, R. C., \& Bilbro, W. C. (1966). The diagnosis of twin zygosity. Human Heredity, 16, 265-275.

Osgood, D. W., Ruth, G., Eccles, J. S., Jacobs, J. E., \& Barber, B. L. (2005). Six paths to adulthood: Fast starters, parents without careers, educated partners, educated singles, working singles, and slow starters. In On the frontier of adulthood: Theory, research, and public policy (pp. 320-355). The University of Chicago Press. https://doi.org/10.7208/chicago/9780226748924.003.0010

Otero, T. M., Barker, L. A., \& Naglieri, J. A. (2014). Executive function treatment and intervention in schools. Applied Neuropsychology. Child, 3(3), 205-214. https://doi.org/10.1080/21622965.2014.897903

Owens, S. F., Rijsdijk, F., Picchioni, M. M., Stahl, D., Nenadic, I., Murray, R. M., \& Toulopoulou, T. (2011). Genetic overlap between schizophrenia and selective components of executive function. Schizophrenia Research, 127(1), 181-187. https://doi.org/10.1016/j.schres.2010.10.010

Price, T. S., \& Jaffee, S. R. (2008). Effects of the family environment: Gene-environment interaction 
and passive gene-environment correlation. Developmental Psychology, 44(2), 305-315. https://doi.org/10.1037/0012-1649.44.2.305

Rhea, S.-A., Gross, A. A., Haberstick, B. C., \& Corley, R. P. (2006). Colorado Twin Registry. Twin Research and Human Genetics: The Official Journal of the International Society for Twin Studies, 9(6), 941-949. https://doi.org/10.1375/183242706779462895

Riva, D., Nichelli, F., \& Devoti, M. (2000). Developmental aspects of verbal fluency and confrontation naming in children. Brain and Language, 71, 267-284.

Robson, D. A., Allen, M. S., \& Howard, S. J. (2020). Self-regulation in childhood as a predictor of future outcomes: A meta-analytic review. Psychological Bulletin, 146(4), 324-354. https://doi.org/10.1037/bul0000227

Sakakibara, E., Takizawa, R., Kawakubo, Y., Kuwabara, H., Kono, T., Hamada, K., Okuhata, S., Eguchi, S., Ishii-Takahashi, A., \& Kasai, K. (2018). Genetic influences on prefrontal activation during a verbal fluency task in children: A twin study using near-infrared spectroscopy. Brain and Behavior, 8(6), e00980. https://doi.org/10.1002/brb3.980

Samuels, W. E., Tournaki, N., Blackman, S., \& Zilinski, C. (2016). Executive functioning predicts academic achievement in middle school: A four-year longitudinal study. The Journal of Educational Research, 109(5), 478-490. https://doi.org/10.1080/00220671.2014.979913

Sauzéon, H., Lestage, P., Raboutet, C., N’Kaoua, B., \& Claverie, B. (2004). Verbal fluency output in children aged 7-16 as a function of the production criterion: Qualitative analysis of clustering, switching processes, and semantic network exploitation. Brain and Language, 89, $192-202$.

Snyder, H. R., \& Munakata, Y. (2010). Becoming self-directed: Abstract representations support endogenous flexibility in children. Cognition, 116, 155-167.

Snyder, H. R., \& Munakata, Y. (2013). So many options, so little control: Abstract representations can reduce selection demands to increase children's self-directed flexibility. Journal of 
Experimental Child Psychology, 116(3), 659-673.

St Clair-Thompson, H. L., \& Gathercole, S. E. (2006). Executive functions and achievements in school: Shifting, updating, inhibition, and working memory. Quarterly Journal of Experimental Psychology (2006), 59(4), 745-759. https://doi.org/10.1080/17470210500162854

Stubbe, J. H., Posthuma, D., Boomsma, D. I., \& De Geus, E. J. C. (2005). Heritability of life satisfaction in adults: A twin-family study. Psychological Medicine, 35(11), 1581-1588. https://doi.org/10.1017/S0033291705005374

Stucke, N., Stoet, G., \& Doebel, S. (2021). What are the kids doing? Children's time use and relations with executive function during the COVID-19 pandemic. [Under review].

Swan, G. E., \& Carmelli, D. (2002). Impaired olfaction predicts cognitive decline in nondemented older adults. Neuroepidemiology, 21(2), 58-67. https://doi.org/10.1159/000048618

Takacs, Z. K., \& Kassai, R. (2019). The efficacy of different interventions to foster children's executive function skills: A series of meta-analyses. Psychological Bulletin, 145(7), 653-697. https://doi.org/10.1037/bul0000195

Troyer, A. K., Moscovitch, M., \& Winocur, G. (1997). Clustering and switching as two components of verbal fluency: Evidence from younger and older healthy adults. Neuropsychology, 11(1), $138-146$.

Troyer, A. K., Moscovitch, M., Winocur, G., Alexander, M. P., \& Stuss, D. (1998). Clustering and switching on verbal fluency: The effects of focal frontal- and temporal-lobe lesions. Neuropsychologia, 36, 499.

Unsworth, N., Brewer, G. A., \& Spillers, G. J. (2011). Variation in working memory capacity and forgetting over both the short and the long term: An application of the population dilution model. Journal of Cognitive Psychology, 23(2), 243-255. https://doi.org/10.1080/20445911.2011.493153

Unsworth, N., Spillers, G. J., \& Brewer, G. A. (2012). Working memory capacity and retrieval 
limitations from long-term memory: An examination of differences in accessibility. Quarterly Journal of Experimental Psychology, 65(12), 2397-2410.

https://doi.org/10.1080/17470218.2012.690438

Vandewater, E. A., Rideout, V. J., Wartella, E. A., Huang, X., Lee, J. H., \& Shim, M. (2007). Digital childhood: Electronic media and technology use among infants, toddlers, and preschoolers. Pediatrics, 119(5), e1006-1015. https://doi.org/10.1542/peds.2006-1804

Wechsler, D. (1974). Manual for the Wechsler Intelligence Scale for children. Psychological Corporation.

Welsh, M. C. (1991). Rule-guided behavior and self-monitoring on the tower of hanoi disk-transfer task. Cognitive Development, 6(1), 59-76. https://doi.org/10.1016/0885-2014(91)90006-Y

West, S. G., Finch, J. F., \& Curran, P. J. (1995). Structural equation models with nonnormal variables: Problems and remedies. In Structural equation modeling: Concepts, issues, and applications (pp. 56-75). Sage Publications, Inc. 


\section{Appendix A}

\section{Correlations across structured activity and verbal fluency measures}

Table A.1: Heterogeneous Correlation Matrix Relating Study Variables (Pearson and Polychoric Estimates*)

\begin{tabular}{|c|c|c|c|c|c|c|c|c|c|c|c|}
\hline & Variable & 1 & 2 & 3 & 4 & 5 & 6 & 7 & 8 & 9 & 10 \\
\hline 1 & Y4 Gfactor & & & & & & & & & & \\
\hline 2 & Y7 Gfactor & .60 & & & & & & & & & \\
\hline 3 & Y16 Gfactor & .49 & .66 & & & & & & & & \\
\hline 4 & Y4 Vocabulary & .53 & .37 & .3 & & & & & & & \\
\hline 5 & Y7 Vocabulary & .44 & .58 & .34 & .42 & & & & & & \\
\hline 6 & Y16 Vocabulary & .46 & .53 & .58 & .39 & .56 & & & & & \\
\hline 7 & Parent Occupation & .20 & .29 & .26 & .31 & .24 & .33 & & & & \\
\hline 8 & Y4 CBCL Structured & .13 & .08 & .01 & .02 & .19 & -.04 & .09 & & & \\
\hline 9 & Y4 CBCL Club & .04 & .11 & .11 & .03 & .07 & -.01 & .01 & .09 & & \\
\hline 10 & Y4 CBCL Chores & .03 & .04 & .11 & .09 & -.02 & .10 & -.01 & .13 & .21 & \\
\hline 11 & Y3 FES Control & .00 & -.15 & -.02 & -.18 & -.2 & -.2 & -.14 & .02 & .12 & .14 \\
\hline 12 & Y3 FES Organization & .00 & -.11 & -.01 & -.13 & -.01 & -.05 & -.04 & .20 & .10 & .13 \\
\hline 13 & Y7 CBCL Chores & .06 & .06 & .11 & .09 & .03 & .06 & -.04 & -.08 & .09 & .24 \\
\hline 14 & Y7 CBCL Structured & .07 & .10 & .12 & .06 & .06 & .10 & .15 & .22 & .11 & .08 \\
\hline 15 & Y7 IAS Lessons & .11 & .12 & .15 & .06 & .15 & .14 & .20 & .31 & .16 & .03 \\
\hline 16 & Y7 FES Control & -.13 & -.12 & -.05 & -.06 & -.16 & -.10 & -.17 & -.08 & .06 & .13 \\
\hline 17 & Y7 FES Organization & .11 & -.01 & .03 & -.01 & .00 & -.04 & .05 & .10 & .17 & .20 \\
\hline 18 & Y16 CBCL Club & .08 & .23 & .29 & .16 & .18 & .16 & .18 & .10 & .27 & .19 \\
\hline 19 & Y16 CBCL Chores & -.01 & .05 & .00 & .09 & .05 & .04 & -.03 & -.04 & .07 & .16 \\
\hline 20 & Y15 FES Control & .01 & .02 & .11 & -.08 & -.04 & -.09 & -.07 & .06 & .14 & .21 \\
\hline 21 & Y15 FES Organization & .00 & -.03 & .10 & -.21 & -.08 & -.04 & -.02 & .01 & .17 & -.01 \\
\hline 22 & Y4 VFsoft Total & .32 & .16 & .14 & .27 & .18 & .16 & .17 & .07 & .13 & .06 \\
\hline 23 & Y4 VFsoft Switch & .19 & .13 & .10 & .18 & .20 & .15 & .08 & .07 & .08 & .11 \\
\hline 24 & Y4 VFnoise Total & .35 & .18 & .11 & .26 & .20 & .17 & .06 & .12 & -.02 & .02 \\
\hline 25 & Y4 VFnoise Switch & .32 & .17 & .18 & .24 & .19 & .22 & .03 & .06 & -.04 & .07 \\
\hline 26 & Y4 VFround Total & .41 & .31 & .23 & .25 & .25 & .30 & .21 & .05 & -.03 & .04 \\
\hline 27 & Y4 VFround Switch & .27 & .21 & .16 & .13 & .17 & .16 & .12 & .09 & -.06 & -.10 \\
\hline 28 & Y7 VFround Total & .22 & .45 & .26 & .24 & .28 & .20 & .20 & .11 & .07 & -.03 \\
\hline 29 & Y7 VFround Switch & .10 & .29 & .15 & .14 & .15 & .18 & .22 & .09 & .02 & -.03 \\
\hline 30 & Y7 VFmetal Total & .08 & .31 & .14 & .12 & .25 & .17 & .12 & -.05 & .00 & -.06 \\
\hline
\end{tabular}




\begin{tabular}{|c|c|c|c|c|c|c|c|c|c|c|c|}
\hline & Variable & & & & & & & & & & \\
\hline 31 & Y7 VFmetal Switch & .04 & .21 & .09 & .10 & .18 & .12 & .09 & -.06 & -.08 & -.08 \\
\hline 32 & Y7 VFanimal Total & .30 & .51 & .35 & .29 & .38 & .39 & .19 & .01 & -.01 & -.03 \\
\hline 33 & Y7 VFanimal Switch & .26 & .43 & .27 & .23 & .30 & .32 & .13 & .01 & .01 & -.04 \\
\hline 34 & Y16 VFmetal Total & .15 & .36 & .52 & .11 & .25 & .38 & .16 & .05 & .04 & .12 \\
\hline 35 & Y16 VFmetal Switch & .12 & .33 & .44 & .11 & .23 & .32 & .12 & .02 & .01 & .13 \\
\hline 36 & Y16 VFround Total & .17 & .32 & .51 & .15 & .21 & .28 & .16 & .02 & .09 & .12 \\
\hline 37 & Y16 VFround Switch & .05 & .22 & .37 & .08 & .11 & .21 & .10 & -.03 & .01 & .08 \\
\hline 38 & Y4 VFsoft Cluster & .25 & .20 & .25 & .24 & .21 & .27 & .06 & .09 & .06 & .04 \\
\hline 39 & Y4 VFnoise Cluster & .32 & .15 & .19 & .23 & .18 & .19 & .02 & .06 & -.03 & .05 \\
\hline 40 & Y4 VFround Cluster & .38 & .25 & .24 & .19 & .29 & .26 & .12 & .10 & .02 & -.01 \\
\hline 41 & Y7 VFround Cluster & .07 & .15 & .10 & .10 & .10 & .13 & .11 & .06 & .02 & .02 \\
\hline 42 & Y7 VFmetal Cluster & -.04 & .09 & -.08 & .00 & .08 & .06 & .01 & .01 & -.03 & -.05 \\
\hline 43 & Y7 VFanimal Cluster & .00 & .05 & -.09 & .02 & .06 & .04 & -.02 & .08 & -.01 & -.04 \\
\hline 44 & Y16 VFmetal Cluster & -.01 & .10 & .24 & .02 & .08 & .16 & .00 & -.05 & .03 & .10 \\
\hline \multirow[t]{2}{*}{45} & Y16 VFround Cluster & -.04 & .06 & .09 & .01 & -.03 & .03 & .00 & -.06 & -.04 & .03 \\
\hline & & 11 & 12 & 13 & 14 & 15 & 16 & 17 & 18 & 19 & 20 \\
\hline 1 & Y4 Gfactor & & & & & & & & & & \\
\hline 2 & Y7 Gfactor & & & & & & & & & & \\
\hline 3 & Y16 Gfactor & & & & & & & & & & \\
\hline 4 & Y4 Vocabulary & & & & & & & & & & \\
\hline 5 & Y7 Vocabulary & & & & & & & & & & \\
\hline 6 & Y16 Vocabulary & & & & & & & & & & \\
\hline 7 & Parent Occupation & & & & & & & & & & \\
\hline 8 & Y4 CBCL Structured & & & & & & & & & & \\
\hline 9 & Y4 CBCL Club & & & & & & & & & & \\
\hline 10 & Y4 CBCL Chores & & & & & & & & & & \\
\hline 11 & Y3 FES Control & & & & & & & & & & \\
\hline 12 & Y3 FES Organization & .45 & & & & & & & & & \\
\hline 13 & Y7 CBCL Chores & .14 & .12 & & & & & & & & \\
\hline 14 & Y7 CBCL Structured & -.04 & -.08 & .07 & & & & & & & \\
\hline 15 & Y7 IAS Lessons & -.06 & -.02 & .15 & .36 & & & & & & \\
\hline 16 & Y7 FES Control & .32 & .20 & .05 & .05 & -.04 & & & & & \\
\hline 17 & Y7 FES Organization & .35 & .59 & .12 & -.02 & .07 & .26 & & & & \\
\hline 18 & Y16 CBCL Club & .09 & .05 & .23 & .25 & .24 & .05 & .08 & & & \\
\hline 19 & Y16 CBCL Chores & .13 & .21 & .23 & -.01 & -.11 & .15 & .14 & .15 & & \\
\hline 20 & Y15 FES Control & .35 & .39 & .07 & .00 & -.01 & .44 & .41 & .20 & .04 & \\
\hline 21 & Y15 FES Organization & .18 & .61 & -.14 & .07 & .11 & .19 & .62 & .09 & -.02 & .51 \\
\hline
\end{tabular}




\begin{tabular}{llrrrrrrrrrr}
22 & Y4 VFsoft Total & -.02 & .01 & -.01 & .07 & .08 & .04 & .16 & .00 & .03 & .05 \\
23 & Y4 VFsoft Switch & .07 & .00 & .02 & .01 & .07 & .04 & .11 & .02 & .07 & .04 \\
24 & Y4 VFnoise Total & -.12 & -.10 & -.05 & .12 & .07 & -.02 & -.09 & -.01 & .06 & -.12 \\
25 & Y4 VFnoise Switch & -.08 & -.11 & .07 & .12 & .02 & .02 & -.01 & .02 & .03 & -.09 \\
26 & Y4 VFround Total & .00 & .08 & -.05 & -.02 & .05 & -.03 & .12 & .16 & .14 & .02 \\
27 & Y4 VFround Switch & -.04 & -.02 & -.10 & -.02 & .12 & -.03 & .06 & .02 & -.03 & -.11 \\
28 & Y7 VFround Total & -.11 & -.05 & .09 & .07 & .08 & .03 & .02 & .21 & -.03 & .10 \\
29 & Y7 VFround Switch & -.10 & -.02 & .09 & -.06 & .08 & .01 & .03 & .03 & .05 & .00 \\
30 & Y7 VFmetal Total & -.04 & .07 & .03 & -.05 & -.03 & -.02 & -.05 & .07 & .01 & -.04 \\
31 & Y7 VFmetal Switch & -.08 & .01 & .04 & -.04 & -.04 & .00 & -.03 & .12 & .02 & -.04 \\
32 & Y7 VFanimal Total & -.15 & -.11 & .13 & -.03 & .06 & .00 & .05 & .19 & .11 & -.06 \\
33 & Y7 VFanimal Switch & -.13 & -.16 & .10 & -.04 & .09 & -.03 & .01 & .10 & .02 & -.09 \\
34 & Y16 VFmetal Total & -.01 & -.09 & .16 & .10 & .17 & .00 & -.05 & .17 & -.07 & -.02 \\
35 & Y16 VFmetal Switch & .01 & -.08 & .16 & .09 & .12 & .00 & -.05 & .13 & -.07 & -.06 \\
36 & Y16 VFround Total & .04 & -.03 & .06 & .03 & .11 & .03 & .04 & .16 & .02 & -.07 \\
37 & Y16 VFround Switch & .03 & .04 & .01 & .05 & .04 & .06 & .03 & .06 & -.03 & -.09 \\
38 & Y4 VFsoft Cluster & -.11 & -.03 & .05 & .12 & .22 & -.07 & .06 & .13 & .00 & -.05 \\
39 & Y4 VFnoise Cluster & -.09 & -.07 & .07 & .10 & .04 & -.03 & .00 & .06 & .01 & -.07 \\
40 & Y4 VFround Cluster & -.05 & .07 & .01 & .05 & .13 & -.12 & .13 & .11 & .11 & .02 \\
41 & Y7 VFround Cluster & -.03 & .02 & .09 & -.05 & .08 & .03 & .09 & .04 & -.01 & .03 \\
42 & Y7 VFmetal Cluster & -.02 & .07 & .06 & -.05 & -.07 & .00 & .01 & .10 & .11 & -.05 \\
43 & Y7 VFanimal Cluster & -.14 & -.04 & .05 & -.02 & .09 & -.03 & -.06 & -.09 & -.16 & -.10 \\
44 & Y16 VFmetal Cluster & .00 & -.04 & .10 & .06 & .03 & -.03 & -.05 & .06 & .00 & -.08 \\
45 & Y16 VFround Cluster & .03 & .03 & -.05 & .09 & .01 & .04 & -.01 & .06 & -.07 & -.12 \\
\hline
\end{tabular}




\begin{tabular}{|c|c|c|c|c|c|c|c|c|c|c|c|}
\hline & Variable & & & & & & & & & & \\
\hline & & 21 & 22 & 23 & 24 & 25 & 26 & 27 & 28 & 29 & $\begin{array}{l}3 \\
0\end{array}$ \\
\hline 1 & Y4 Gfactor & & & & & & & & & & \\
\hline 2 & Y7 Gfactor & & & & & & & & & & \\
\hline 3 & Y16 Gfactor & & & & & & & & & & \\
\hline 4 & Y4 Vocabulary & & & & & & & & & & \\
\hline 5 & Y7 Vocabulary & & & & & & & & & & \\
\hline 6 & Y16 Vocabulary & & & & & & & & & & \\
\hline 7 & Parent Occupation & & & & & & & & & & \\
\hline 8 & Y4 CBCL Structured & & & & & & & & & & \\
\hline 9 & Y4 CBCL Club & & & & & & & & & & \\
\hline 10 & Y4 CBCL Chores & & & & & & & & & & \\
\hline 11 & Y3 FES Control & & & & & & & & & & \\
\hline 12 & Y3 FES Organization & & & & & & & & & & \\
\hline 13 & Y7 CBCL Chores & & & & & & & & & & \\
\hline 14 & Y7 CBCL Structured & & & & & & & & & & \\
\hline 15 & Y7 IAS Lessons & & & & & & & & & & \\
\hline 16 & Y7 FES Control & & & & & & & & & & \\
\hline 17 & Y7 FES Organization & & & & & & & & & & \\
\hline 18 & Y16 CBCL Club & & & & & & & & & & \\
\hline 19 & Y16 CBCL Chores & & & & & & & & & & \\
\hline 20 & Y15 FES Control & & & & & & & & & & \\
\hline 21 & Y15 FES Organization & & & & & & & & & & \\
\hline 22 & Y4 VFsoft Total & .03 & & & & & & & & & \\
\hline 23 & Y4 VFsoft Switch & -.08 & .73 & & & & & & & & \\
\hline 24 & Y4 VFnoise Total & -.07 & .34 & .20 & & & & & & & \\
\hline 25 & Y4 VFnoise Switch & -.01 & .20 & .21 & .72 & & & & & & \\
\hline 26 & Y4 VFround Total & -.04 & .29 & .22 & .28 & .20 & & & & & \\
\hline 27 & Y4 VFround Switch & -.01 & .17 & .17 & .06 & .07 & .51 & & & & \\
\hline 28 & Y7 VFround Total & -.06 & .09 & -.04 & .12 & .07 & .16 & .07 & & & \\
\hline 29 & Y7 VFround Switch & .01 & .04 & -.05 & .00 & .03 & .11 & .03 & .61 & & \\
\hline 30 & Y7 VFmetal Total & .00 & .03 & -.05 & .12 & -.02 & .07 & .00 & .37 & .20 & \\
\hline 31 & Y7 VFmetal Switch & -.05 & -.02 & -.09 & .05 & -.04 & .03 & -.05 & .27 & .21 & .7 \\
\hline 32 & Y7 VFanimal Total & -.22 & .19 & .16 & .15 & .17 & .29 & .18 & .48 & .34 & .35 \\
\hline 33 & Y7 VFanimal Switch & -.18 & .17 & .16 & .11 & .17 & .24 & .16 & .40 & .29 & .29 \\
\hline 34 & Y16 VFmetal Total & .00 & -.01 & .01 & .18 & .19 & .06 & -.01 & .28 & .16 & .26 \\
\hline 35 & Y16 VFmetal Switch & -.05 & .01 & .05 & .16 & .19 & .01 & -.01 & .27 & .17 & .24 \\
\hline 36 & Y16 VFround Total & -.08 & .01 & .01 & .17 & .13 & .12 & .01 & .24 & .13 & .16 \\
\hline
\end{tabular}




\begin{tabular}{|c|c|c|c|c|c|c|c|c|c|c|c|}
\hline & Variable & & & & & & & & & & \\
\hline 37 & Y16 VFround Switch & -.07 & -.10 & -.05 & .11 & .05 & .07 & -.01 & .22 & .10 & .12 \\
\hline 38 & Y4 VFsoft Cluster & .01 & .55 & .41 & .26 & .28 & .16 & .12 & .08 & .08 & .05 \\
\hline 39 & Y4 VFnoise Cluster & -.04 & .16 & .20 & .63 & .78 & .15 & .04 & .04 & -.03 & .05 \\
\hline 40 & Y4 VFround Cluster & .02 & .19 & .20 & .20 & .25 & .65 & .33 & .16 & .13 & .07 \\
\hline 41 & Y7 VFround Cluster & .06 & .02 & -.02 & .00 & .01 & .01 & .00 & .30 & .62 & .13 \\
\hline 42 & Y7 VFmetal Cluster & .05 & -.04 & -.05 & .09 & .04 & .01 & -.04 & .14 & .17 & .46 \\
\hline 43 & Y7 VFanimal Cluster & .02 & -.05 & -.03 & .03 & .03 & .08 & .04 & .02 & .04 & .09 \\
\hline 44 & Y16 VFmetal Cluster & -.04 & -.03 & .02 & .08 & .09 & -.02 & .01 & .05 & .04 & .13 \\
\hline \multirow[t]{2}{*}{45} & Y16 VFround Cluster & -.10 & -.16 & -.09 & -.01 & -.06 & -.04 & -.03 & .09 & .00 & .03 \\
\hline & & 31 & 32 & 33 & 34 & 35 & 36 & 37 & 38 & 39 & 40 \\
\hline 1 & Y4 Gfactor & & & & & & & & & & \\
\hline 2 & Y7 Gfactor & & & & & & & & & & \\
\hline 3 & Y16 Gfactor & & & & & & & & & & \\
\hline 4 & Y4 Vocabulary & & & & & & & & & & \\
\hline 5 & Y7 Vocabulary & & & & & & & & & & \\
\hline 6 & Y16 Vocabulary & & & & & & & & & & \\
\hline 7 & Parent Occupation & & & & & & & & & & \\
\hline 8 & Y4 CBCL Structured & & & & & & & & & & \\
\hline 9 & Y4 CBCL Club & & & & & & & & & & \\
\hline 10 & Y4 CBCL Chores & & & & & & & & & & \\
\hline 11 & Y3 FES Control & & & & & & & & & & \\
\hline 12 & Y3 FES Organization & & & & & & & & & & \\
\hline 13 & Y7 CBCL Chores & & & & & & & & & & \\
\hline 14 & Y7 CBCL Structured & & & & & & & & & & \\
\hline 15 & Y7 IAS Lessons & & & & & & & & & & \\
\hline 16 & Y7 FES Control & & & & & & & & & & \\
\hline 17 & Y7 FES Organization & & & & & & & & & & \\
\hline 18 & Y16 CBCL Club & & & & & & & & & & \\
\hline 19 & Y16 CBCL Chores & & & & & & & & & & \\
\hline 20 & Y15 FES Control & & & & & & & & & & \\
\hline 21 & Y15 FES Organization & & & & & & & & & & \\
\hline 22 & Y4 VFsoft Total & & & & & & & & & & \\
\hline \multirow[t]{2}{*}{23} & Y4 VFsoft Switch 24 & & & & & & & & & & \\
\hline & Y4 VFnoise Total & & & & & & & & & & \\
\hline 25 & Y4 VFnoise Switch & & & & & & & & & & \\
\hline 26 & Y4 VFround Total & & & & & & & & & & \\
\hline 27 & Y4 VFround Switch & & & & & & & & & & \\
\hline 28 & Y7 VFround Total & & & & & & & & & & \\
\hline \multirow[t]{2}{*}{29} & Y7 VFround Switch 30 & & & & & & & & & & \\
\hline & Y7 VFmetal Total & & & & & & & & & & \\
\hline 31 & Y7 VFmetal Switch & & & & & & & & & & \\
\hline 32 & Y7 VFanimal Total & .29 & & & & & & & & & \\
\hline
\end{tabular}




\begin{tabular}{|c|c|c|c|c|c|c|c|c|c|c|c|}
\hline & Variable & & & & & & & & & & \\
\hline 33 & Y7 VFanimal Switch & .22 & .88 & & & & & & & & \\
\hline 34 & Y16 VFmetal Total & .20 & .34 & .29 & & & & & & & \\
\hline 35 & Y16 VFmetal Switch & .20 & .31 & .30 & .87 & & & & & & \\
\hline 36 & Y16 VFround Total & .13 & .27 & .19 & .58 & .49 & & & & & \\
\hline 37 & Y16 VFround Switch & .13 & .15 & .08 & .42 & .43 & .79 & & & & \\
\hline 38 & Y4 VFsoft Cluster & .10 & .21 & .20 & .14 & .12 & .15 & .03 & & & \\
\hline 39 & Y4 VFnoise Cluster & .01 & .13 & .15 & .19 & .16 & .12 & .04 & .31 & & \\
\hline 40 & Y4 VFround Cluster & .08 & .25 & .23 & .13 & .08 & .17 & .07 & .29 & .27 & \\
\hline 41 & Y7 VFround Cluster & .20 & .10 & .07 & .10 & .09 & .06 & .04 & .06 & -.05 & -.03 \\
\hline 42 & Y7 VFmetal Cluster & .63 & .18 & .12 & .06 & .09 & .09 & .12 & .05 & .07 & .07 \\
\hline 43 & Y7 VFanimal Cluster & .06 & .17 & .42 & .03 & .03 & -.07 & -.10 & -.03 & -.02 & .09 \\
\hline 44 & Y16 VFmetal Cluster & .17 & .13 & .17 & .34 & .6 & .17 & .21 & .10 & .08 & -.03 \\
\hline \multirow[t]{2}{*}{45} & Y16 VFround Cluster & .06 & .02 & -.01 & .11 & .20 & .31 & .69 & -.07 & -.06 & -.03 \\
\hline & & 41 & 42 & 43 & 44 & 45 & & & & & \\
\hline
\end{tabular}




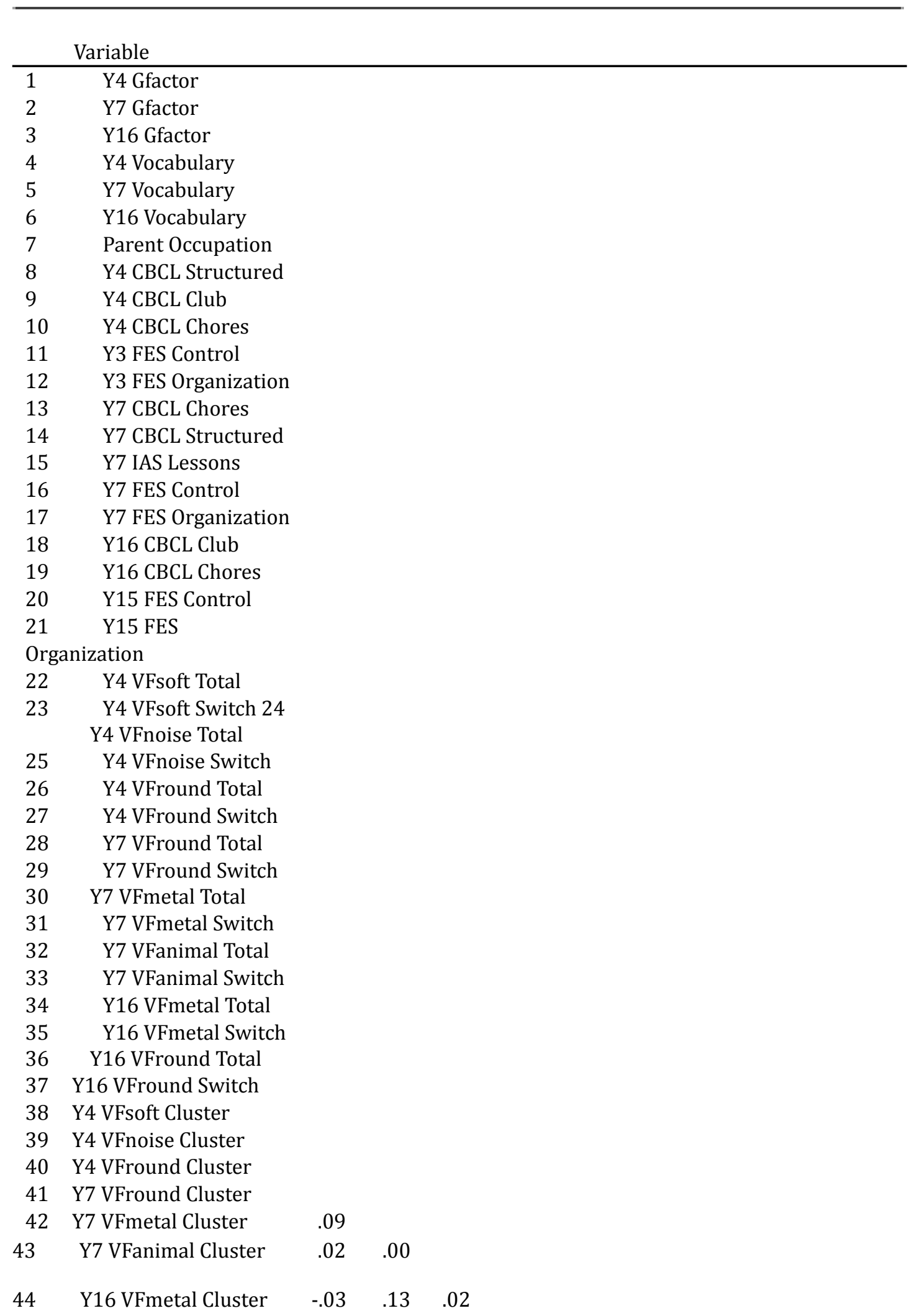




\begin{tabular}{|c|c|c|c|c|c|}
\hline 45 & $\begin{array}{l}\text { Variable } \\
\text { Y16 VFround Cluster }\end{array}$ & -.01 & .09 & -.09 & .17 \\
\hline
\end{tabular}

*Note: to provide estimates unbiased by familial clustering, only Twin 1 correlations shown. 


\section{Appendix B \\ Moos Family Environment Subscales (MFES)}

Each item was measured on a binary scale at age 3 (True/False) on a 5-point Likert scale at ages 7 and 15 (anchored by Strongly disagree = 1; Strongly agree $=5)$. Reverse-coded items indicated with $(\mathrm{R})$.

\begin{tabular}{|c|c|c|c|}
\hline Control Subscale & Age 3 & Age 7 & Age 15 \\
\hline Family members are rarely ordered around. (R) & & $\mathrm{X}$ & \\
\hline There are very few rules to follow in our family. (R) & $\mathrm{X}$ & $\mathrm{X}$ & $\mathrm{X}$ \\
\hline There is one family member who makes most of the decisions. & & $\mathrm{X}$ & \\
\hline There are set ways of doing things at home. & $\mathrm{X}$ & $\mathrm{X}$ & $\mathrm{X}$ \\
\hline There is a strong emphasis on following rules in our family. & $\mathrm{X}$ & $\mathrm{X}$ & $\mathrm{X}$ \\
\hline Everyone has an equal say in family decisions. (R) & & $\mathrm{X}$ & \\
\hline We can do whatever we want to in our family. (R) & & $\mathrm{X}$ & \\
\hline Rules are pretty inflexible in our household. & $\mathrm{X}$ & $\mathrm{X}$ & \\
\hline *Rules are pretty flexible in our household. (R) & & & $\mathrm{X}$ \\
\hline You cant get away with much in our family. & $\mathrm{X}$ & $\mathrm{X}$ & $\mathrm{X}$ \\
\hline Organization Subscale & Age 3 & Age 7 & Age 15 \\
\hline Activities in our family are pretty carefully planned. & & $\mathrm{X}$ & \\
\hline We are generally very neat and orderly. & $\mathrm{X}$ & $\mathrm{X}$ & $\mathrm{X}$ \\
\hline Its often hard to find things when you need them in our household. (R) & & $\mathrm{X}$ & \\
\hline Being on time is very important in our family. & $\mathrm{X}$ & $\mathrm{X}$ & $\mathrm{X}$ \\
\hline People change their minds often in our family. (R) & & $\mathrm{X}$ & \\
\hline Family members make sure their rooms are neat. & $\mathrm{X}$ & $\mathrm{X}$ & $\mathrm{X}$ \\
\hline Each persons duties are clearly defined in our family. & $\mathrm{X}$ & $\mathrm{X}$ & $\mathrm{X}$ \\
\hline Money is not handled very carefully in our family. (R) & & $\mathrm{X}$ & \\
\hline Dishes are usually done immediately after eating. & $\mathrm{X}$ & $\mathrm{X}$ & $\mathrm{X}$ \\
\hline
\end{tabular}




\section{Appendix C \\ Specific Cognitive Battery Subtests used to Derive g-Factor}

Verbal Tasks:

- Vocabulary:

$\circ \quad$ WPPSI (Year 4)

$\circ \quad$ WISC-R (Year 7)

- Other (Year 16)

- Semantic Verbal Fluency (Y4-16)

- Word Beginnings and Endings (Y16)

Spatial Tasks:

- McCarthy Puzzle Solving (Y4)

- WPPSI Block Design (Y4)

- Card Rotation (Y16)

- Ravens Progressive Matrices (Y16)

- Hidden Patterns (Y16)

Perceptual Speed Tasks (Y4-Y16):

- Colorado Perceptual Speed Task

○ Varied Dots

○ Identical Pictures

Memory Tasks (Y4-Y16):

- Picture Memory Immediate Recognition

- Picture Memory Delayed Recognition

Other (Y16):

- Subtraction and Multiplication 